\title{
Baroclinically Induced Tropical Cyclogenesis
}

\author{
Christopher A. DAVIS \\ National Center for Atmospheric Research,* Boulder, Colorado \\ LANCE F. BOSART \\ The University at Albany, State University of New York, Albany, New York
}

(Manuscript received 9 January 2003, in final form 1 May 2003)

\begin{abstract}
The authors investigate the transition of numerous subtropical cyclones into late season tropical storms and hurricanes during the 2000 and 2001 Atlantic tropical cyclone seasons. In all transitioning cases (10), the 900200-hPa wind shear was initially near or in excess of the upper limit of vertical shear deemed suitable for tropical cyclogenesis. In many of these cases, the vertical shear decreased markedly near or prior to the time of tropical cyclone formation. In cases that did not become named tropical cyclones, either the tropospheric vertical shear remained in excess of $15-20 \mathrm{~m} \mathrm{~s}^{-1}$ or the underlying sea surface temperature (SST) dropped below about $26^{\circ} \mathrm{C}$ prior to or during the weakening of the shear. Cases in which the shear remained large featured multiple, shortwave upper-tropospheric troughs interacting with the developing lower-tropospheric disturbance such that classical occlusion did not occur.

Through detailed analysis and simulation of the development of Hurricane Michael in 2000, it was found that the rapid reduction of vertical shear occurred within the precursor baroclinic development. This shear reduction is explained by the diabatic redistribution of potential vorticity, involving both the nonconservative redistribution of potential vorticity (PV) along the three-dimensional vorticity vector and divergent, diabatically induced outflow in the upper troposphere. While some shear reduction occurred in an adiabatic simulation, the diabatic processes were found crucial to reducing the shear on a short $(12 \mathrm{~h})$ timescale. Such a rapid reduction in shear may be particularly important for the formation of late season hurricanes because of the greater poleward steering influence of disturbances in the westerlies that tends to move such storms over cool water.
\end{abstract}

\section{Introduction}

The conditions favorable for tropical cyclogenesis have been elucidated and verified by statistical analysis in many studies (e.g., Gray 1968; DeMaria et al. 2001). In addition to favoring environments with sea surface temperatures (SST) greater than about $26.5^{\circ} \mathrm{C}$, divergence in the upper troposphere, consistent with deep, organized ascent, a moist lower to middle troposphere and a finite-amplitude near-surface cyclonic circulation is the requirement of weak vertical wind shear. While there is no unambiguous threshold defining "weak," it is generally believed that tropical cyclogenesis is extremely unlikely when the magnitude of the 850-200$\mathrm{hPa}$ shear exceeds about $15 \mathrm{~m} \mathrm{~s}^{-1}$ (DeMaria et al. 2001). Gallina and Velden (2002) have noted that Atlantic trop-

\footnotetext{
* The National Center for Atmospheric Research is sponsored by the National Science Foundation.

Corresponding author address: Christopher A. Davis, National Center for Atmospheric Research, P.O. Box 3000, Boulder, CO 80307. E-mail: cdavis@ucar.edu
}

ical cyclones are unlikely to intensify if the background vertical shear exceeds even half that value.

While the previous conditions are arguably informative indicators of Atlantic tropical cyclone formation in deep easterlies equatorward of about $20^{\circ} \mathrm{N}$, there is evidence that many tropical cyclones forming further north are influenced by extratropical weather systems and their attendant large vertical wind shear, both from a theoretical (Montgomery and Farrell 1993) and observational perspective (Vega and Binkley 1994; Bracken and Bosart 2000). Bracken and Bosart (2000) composited the synoptic-scale flow associated with developing and decaying tropical disturbances over the northern Caribbean Sea and found that the incipient low-level cyclone was typically located beneath the inflection point between an upshear trough and downshear ridge. Quasigeostrophic theory was used to characterize this location as consisting of gentle, subsynoptic-scale upward motion, for which a nontrivial vertical shear was crucial. Thus, Bracken and Bosart demonstrated that not only can tropical depressions develop in the presence of vertical shear, they suggested that the shear might be necessary. Note that the mean tropospheric vertical wind 
shear averaged over their sample of developing depressions was about $10.5 \mathrm{~m} \mathrm{~s}^{-1}$, actually higher than the threshold found by Gallina and Velden (2002) for intensifying hurricanes. We are thus forced to reconcile the apparent need for finite vertical shear to initiate development with the notion that shear impedes development.

Examples exist of subtropical baroclinic cyclones that transition into tropical storms and hurricanes (referred to as transitioning storms herein). Bosart and Bartlo (1991) studied the development of Diana in 1984, a storm that developed to the east of Florida from a coldcore baroclinic cyclone. While of somewhat greater amplitude, the overall synoptic-scale structure in this case was much like that shown in Bracken and Bosart (2000). Davis and Bosart (2001) showed that balanced vertical motion (in shear) initiated deep convection that produced mesoscale potential vorticity (PV) anomalies prior to the formation of Diana. Intensification of a single anomaly, combined with the merger of surrounding anomalies, resulted in a mesoscale, warm-core vortex capable of self-amplification through air-sea interaction. In this case, baroclinity was critical for producing a region of quasi-balanced upward motion within which convection was focused, but Powers and Davis (2002) showed that the intensification of the resulting depression to hurricane strength depended upon the weakening of the overall vertical shear at later times.

The present paper first features a synthesis of diagnostic calculations performed on global analyses for numerous Atlantic cyclones occurring during the latter half of the 2000 and 2001 hurricane seasons (section 3). A total of 10 tropical cyclones and 14 extratropical or subtropical cyclones are examined. In all of the tropical cyclone cases, an extratropical cyclone preceded development, as did vertical shear exceeding the empirical criterion for Atlantic tropical cyclone intensification found by Gallina and Velden (2002). We then focus on one particular case, Michael in 2000, and use numerical simulations to address the dynamics responsible for conditioning the atmosphere for tropical cyclogenesis (section 4).

More generally, this paper suggests a range of possible behavior based on the intensity of the baroclinic precursor to tropical cyclones. In stronger baroclinic cases, baroclinic and diabatic processes combine to yield an intense mesoscale cyclone, either extratropical or subtropical in nature that then transitions to a tropical cyclone. In weaker baroclinic cases, we hypothesize that the baroclinic structure efficiently organizes convection and diabatic heating, which subsequently reduces the shear and produces the incipient tropical disturbance. In these latter cases, baroclinic cyclogenesis is a trivial aspect.

\section{Methodology}

Our approach may be separated into two parts, the analysis of global datasets and the analysis of mesoscale simulations. The global analyses are used to analyze the synoptic-scale disturbances and the environment of tropical disturbances that develop. Simulations are used to examine the dynamics responsible for weakening the shear and for transforming the internal storm structure from cold to warm core.

We utilize the Aviation (AVN) model analyses provided on a $1^{\circ} \times 1^{\circ}$ latitude-longitude grid by the $\mathrm{Na}$ tional Centers for Environmental Prediction (NCEP). To facilitate analysis, and to provide initial and boundary conditions for numerical simulations, these data are interpolated to a Mercator grid with the same grid spacing as the original data. Data are provided on 21 mandatory pressure levels up to $50 \mathrm{hPa}$, with $25 \mathrm{hPa}$ spacing between 1000 and $900 \mathrm{hPa}$. Wind, temperature, and relative humidity are provided at 6-h intervals.

We define the center of circulation for each storm by a local maximum of relative vorticity at $900 \mathrm{hPa}$ averaged over a $3 \times 3$ square $(333 \mathrm{~km} \times 333 \mathrm{~km})$. Environmental parameters such as vertical wind shear and relative humidity are averaged over a somewhat larger $5 \times 5$ grid centered on the storm. Unless otherwise stated, the vertical shear is the mean in the 900-200$\mathrm{hPa}$ layer.

We also use the global analyses as a background for initializing the fifth-generation Pennsylvania State University-National Center for Atmospheric Research Mesoscale Model, release 3.5 (MM5; Grell et al. 1994). All simulations consist of a 3-domain configuration with grid spacings of 111,37 , and $12.3 \mathrm{~km}$ on domains 1 , 2 , and 3 respectively. We use 37 terrain-following levels, stretched from about $20-\mathrm{m}$ vertical resolution near the surface to more than 500-m spacing near the lid at 50 $\mathrm{hPa}$. The lowest level is about $10 \mathrm{~m}$ above the surface.

All simulations use the Blackadar scheme for the planetary boundary layer, the 3-category Numerical Weather Prediction Explicit Microphysics scheme (NEM; Schultz 1995), the Dudhia (1989) radiation scheme and the Kain-Fritsch cumulus scheme (Kain and Fritsch 1993). Considerable success was shown using the Kain-Fritsch and NEM schemes in the simulation of Diana in 1984 by Davis and Bosart (2001), although it was recognized that there was significant sensitivity to the choice of physical parameterization in that case. The Blackadar scheme (Zhang and Anthes 1982) is used because it has been shown to produce reasonable results for hurricane simulations (Braun and Tao 2000). Simulations are initialized directly from the AVN data without reanalyzing other observations.

\section{Data analysis \\ a. Transitioning storms during 2000 and 2001}

During the latter parts of the 2000 and 2001 tropical cyclone seasons, there were many tropical storms and hurricanes that arose in sheared environments and featured extratropical characteristics prior to their transition 
TABLE 1. Shears (900-200 hPa) for transitioning storms.

\begin{tabular}{|c|c|c|c|c|c|c|c|}
\hline Storm & Start date & $\begin{array}{l}\text { Initial shear } \\
\left(\mathrm{m} \mathrm{s}^{-1}\right)\end{array}$ & $\begin{array}{l}\text { Lat }\left({ }^{\circ} \mathrm{N}\right) / \\
\text { Lon }\left({ }^{\circ} \mathrm{W}\right)\end{array}$ & Time & $\begin{array}{l}\text { Min shear } \\
\left(\mathrm{m} \mathrm{s}^{-1}\right)\end{array}$ & $\begin{array}{l}\text { Lat }\left({ }^{\circ} \mathrm{N}\right) / \\
\text { Lon }\left({ }^{\circ} \mathrm{W}\right)\end{array}$ & Time \\
\hline \multicolumn{8}{|l|}{2000} \\
\hline Florence & 0600 UTC 11 Sep & 14 & $30 / 67$ & 0000 UTC 9 Sep & 1 & $30 / 74$ & 1200 UTC 11 Sep \\
\hline Leslie & 1200 UTC 5 Oct & 12 & $30 / 81$ & 0000 UTC 5 Oct & 6 & $30 / 75$ & 0000 UTC 6 Oct \\
\hline Michael & 0000 UTC 17 Oct & 32 & $26 / 72$ & 0000 UTC 13 Oct & 3 & $20 / 71$ & 0000 UTC 18 Oct \\
\hline Nadine & 1200 UTC 20 Oct & 8 & $25 / 61$ & 0000 UTC 19 Oct & 6 & $27 / 60$ & 1200 UTC 19 Oct \\
\hline \multicolumn{8}{|l|}{2001} \\
\hline Gabrielle & 1800 UTC $13 \mathrm{Sep}$ & 10 & $27 / 84$ & 1200 UTC $10 \mathrm{Sep}$ & 2 & $25 / 86$ & 0000 UTC 13 Sep \\
\hline Humberto & 1200 UTC $22 \mathrm{Sep}$ & 13 & $25 / 65$ & 0000 UTC 21 Sep & 5 & $32 / 67$ & 0000 UTC 24 Sep \\
\hline Karen & 0600 UTC 13 Oct & 30 & $30 / 64$ & 1200 UTC 11 Oct & 4 & $32 / 66$ & 1200 UTC 12 Oct \\
\hline Lorenzo & 0000 UTC 30 Oct & 12 & $28 / 37$ & 0000 UTC 28 Oct & 1 & $29 / 45$ & 0000 UTC 30 Oct \\
\hline Noel & 0000 UTC 5 Nov & 39 & $30 / 48$ & 1200 UTC 1 Nov & 10 & $34 / 51$ & 1200 UTC 4 Nov \\
\hline Olga & 1200 UTC 24 Nov & 13 & $30 / 52$ & 0000 UTC $23 \mathrm{Nov}$ & 2 & $30 / 56$ & 1200 UCT 26 Nov \\
\hline
\end{tabular}

to tropical cyclones. In Table 1, we have listed the tropical cyclones that developed poleward of $20^{\circ} \mathrm{N}$ during the periods September-October 2000 and SeptemberNovember 2001.

Vertical wind shear was calculated by averaging the 900-200-mb shear from the NCEP analyses over an area of $5^{\circ}$ by $5^{\circ}$ centered on the 900 -hPa vorticity maximum. All of these transitioning storms were identified with larger shear early in their development rather than later. In most of the storms in Table 1, the initial vertical shears are near or greater than the empirically defined upper limit of $12-15 \mathrm{~m} \mathrm{~s}^{-1}$, above which tropical cyclogenesis is not observed (Gray 1968; DeMaria et al. 2001). Gallina and Velden (2002) found that a more stringent threshold shear about $8 \mathrm{~m} \mathrm{~s}^{-1}$ separates developing and nondeveloping Atlantic tropical cyclones. All the initial shears in Table 1 exceed this latter threshold. In all cases in the table, the shear eventually decreases to $10 \mathrm{~m} \mathrm{~s}^{-1}$ or less during, or just prior to, the transformation of these systems to tropical storms. In most cases, the minimum shear is $6 \mathrm{~m} \mathrm{~s}^{-1}$ or less.

Some noteworthy cases occurred among the sample of developing storms. Michael in 2000 (Fig. 1a) and Karen in 2001 (Fig. 1b) featured strong baroclinic cyclogenesis prior to tropical cyclone formation. Both cases featured low-latitude penetrations of strong anticyclones and deep intrusions of stratospheric PV air into the troposphere.

Leslie in 2000 (Fig. 1c), never becoming more than a marginal tropical storm, developed along a stalled frontal boundary over northern Florida in an environment of weak deep-layer shear, but relatively strong lower-tropospheric shear due to the front. Leslie evolved characteristics of an extratropical storm very early in its life cycle as the deep-layer shear increased. The shear over the storm center then decreased as the storm developed an occluded structure and the scale of the cyclonic vortex contracted, signaling its transition to a tropical storm.

Humberto in 2000 (Fig. 1d) experienced only modest shear in its early stages, but nonetheless was influenced by a southward extrusion of a narrow filament of high
PV in the upper troposphere. As can be inferred from Fig. 1, its initial development resembled the formation of Diana in 1984 although the disturbance was weaker prior to Humberto. In Davis and Bosart (2001) it was shown that balanced, vertical motion associated with the synoptic-scale PV anomalies focused convection that then organized into Diana. In Humberto, a similar focusing of convection by the larger-scale flow is suggested (Fig. 2). The location of the deep convection prior to Humberto is directly downshear from the positive PV anomaly in the upper troposphere (at the time shown in Fig. 2, the deep-layer shear over the center of the depression is directed toward the east-northeast at about $5 \mathrm{~m} \mathrm{~s}^{-1}$ ). We computed the adiabatic, nonlinear-balanced vertical motion according to the method presented in Davis and Emanuel (1991) and found weak lowertropospheric lifting (about $0.2 \mathrm{~cm} \mathrm{~s}^{-1}$ ) collocated with the deep convection over the center of the developing circulation. Although slightly smaller in scale, the synoptic-scale pattern is fully consistent with the composite of northern Caribbean developing depressions presented by Bracken and Bosart (2000). Therein, upward motion was inferred downshear from the upper-tropospheric trough based on the quasigeostrophic omega equation.

\section{b. Nontransitioning storms}

Numerous cyclones with significant circulations over warm water did not become tropical cyclones during the period of interest. In Table 2, we have listed all nontropical cyclones that developed poleward of $20^{\circ} \mathrm{N}$ during the periods September-October 2000 and September-November 2001 and that satisfied the following conditions:

- 900-hPa vorticity maxima exceeded $5 \times 10^{-5} \mathrm{~s}^{-1}(3$ $\times 3$ box average) for at least $24 \mathrm{~h}$,

- center persisted over ocean surface temperatures greater than $25^{\circ} \mathrm{C}$ for at least $24 \mathrm{~h}$, and

- storm developed poleward of $20^{\circ} \mathrm{N}$ and not in deep easterlies.

For a uniform distribution of vorticity, this threshold 


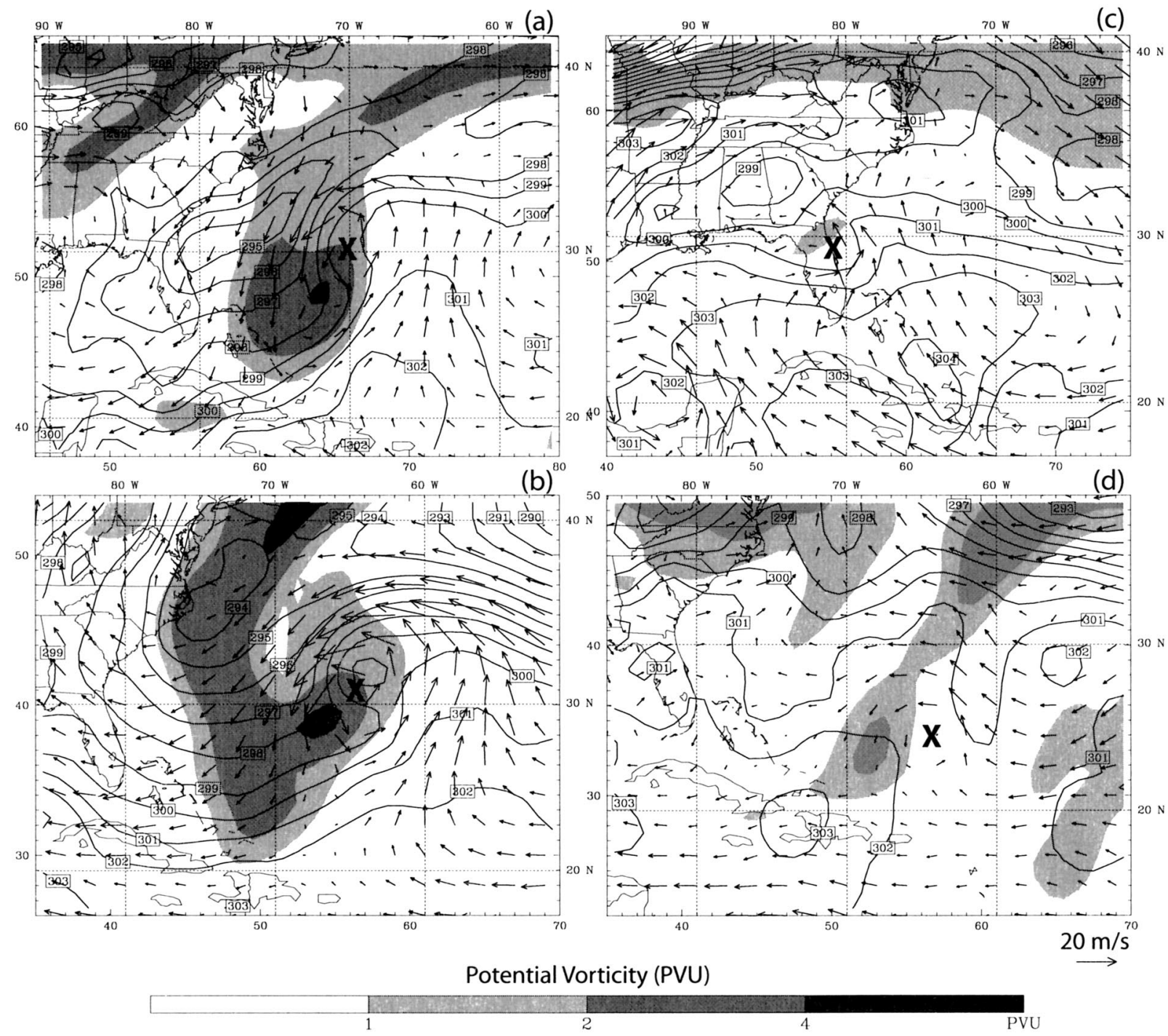

FIG. 1. Wind and temperature (1-K interval) at $900 \mathrm{hPa}$ and PV on the $340-\mathrm{K}$ isentropic surface (PVU) from AVN analyses valid (a) 1200 UTC 15 Oct (pre-Michael); (b) 0000 UTC 12 Oct (pre-Karen); and (c) 1200 UTC 4 Oct 2000 (pre-Leslie); and (d) 1200 UTC 21 Sep 2001 (pre-Humberto).

vorticity is equivalent to an average cyclonic wind around the perimeter of the $3 \times 3$ box of about $4 \mathrm{~m}$ $\mathrm{s}^{-1}$.

In most cases listed in Table 2, the shear did not weaken below the empirically determined thresholds conducive for tropical cyclogenesis. In other cases, the shear did weaken, but the storm moved over cool water and did not develop tropical characteristics. While the initial vertical shear of transitioning cases appears slightly weaker, on average, than the initial vertical shear associated with nontransitioning cases, the primary distinction among cases remaining over SST $>26^{\circ} \mathrm{C}$ is the markedly lower shears just prior to or during tropical cyclogenesis in the transitioning cases.

One factor characterizing nontransitioning cases in which the shear did not weaken was the presence of multiple upper-tropospheric disturbances of comparable amplitude and relatively small spatial and temporal separation that affected cyclones during their developing phase. An example was the storm of early October 2000 (Figs. 3a,b). Following incipient cyclogenesis associated with a remnant baroclinic zone and the southern end of a fractured trough in the westerlies (broadly similar to the early stages of Diana in 1984) a second, stronger trough maintained the shear over the storm center as it approached. In this case, the second phase of development appeared to increase the poleward translation of the storm, thus moving it over cool water before equilibration of this second phase of cyclogenesis could transpire.

The presence of the two troughs was quantified by computing a time series of the negative of relative vor- 


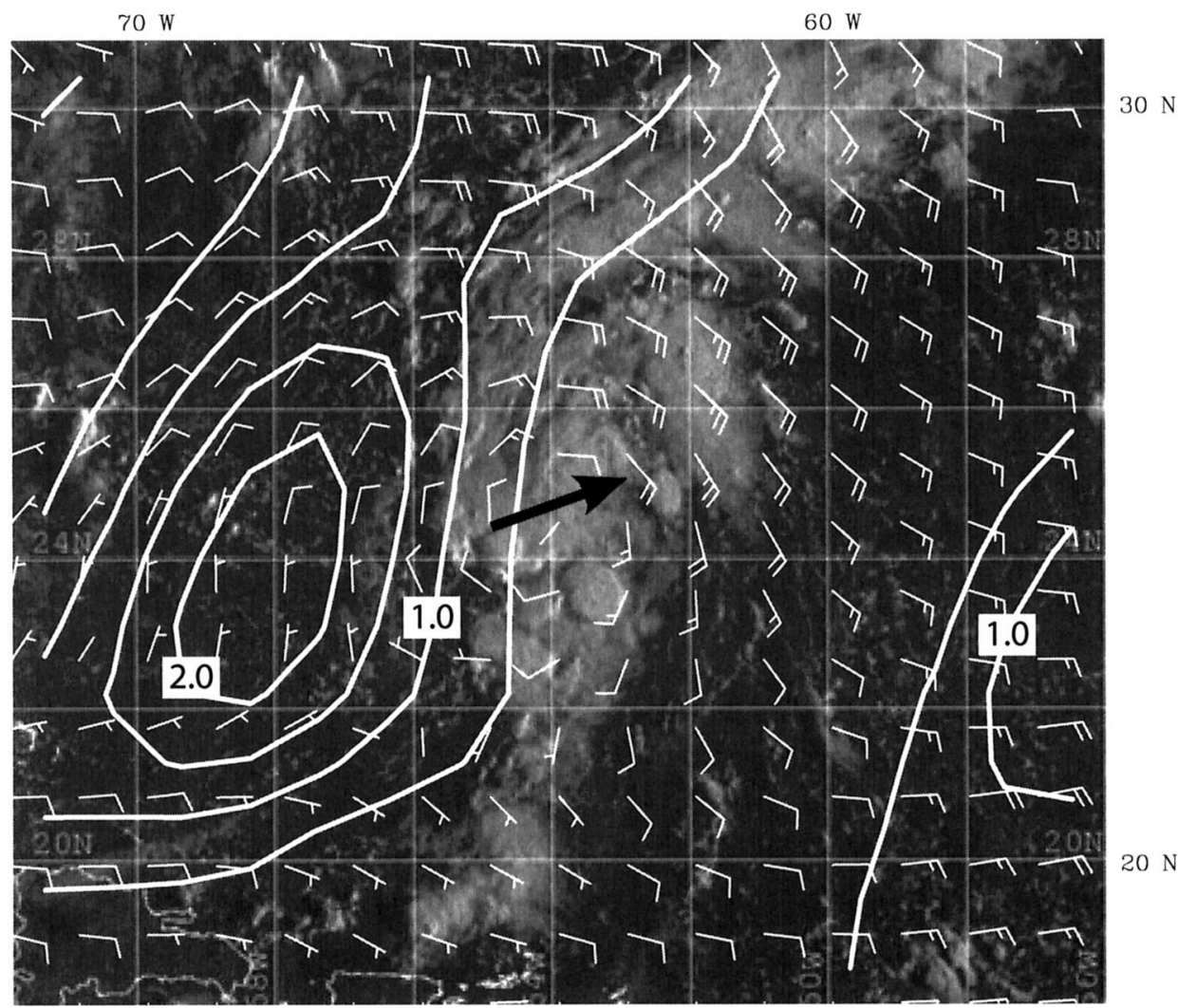

FIG. 2. Here, 340-K PV (PVU) and 900-hPa wind barbs (long barb $=5 \mathrm{~m} \mathrm{~s}^{-1}$ ) from AVN analysis valid 1200 UTC 21 Sep 2001, overlayed on visible satellite image from corresponding time. The heavy black arrow represents the deep-layer shear direction over the storm center (magnitude $=5 \mathrm{~m} \mathrm{~s}^{-1}$ ).

TABLE 2. Nontransitioning storms. Duration of event is period when storm exceeded minimum circulation and SST requirements (see text).

\begin{tabular}{|c|c|c|c|c|c|}
\hline Dates & $\begin{array}{l}\text { Initial shear } \\
\left(\mathrm{m} \mathrm{s}^{-1}\right)\end{array}$ & $\begin{array}{l}\text { Lat }\left({ }^{\circ} \mathrm{N}\right) / \\
\text { Lon }\left({ }^{\circ} \mathrm{W}\right)\end{array}$ & $\begin{array}{l}\text { Min shear } \\
\left(\mathrm{m} \mathrm{s}^{-1}\right)\end{array}$ & $\begin{array}{l}\text { Lat }\left({ }^{\circ} \mathrm{N}\right) / \\
\text { Lon }\left({ }^{\circ} \mathrm{W}\right)\end{array}$ & Remarks \\
\hline \multicolumn{6}{|l|}{2000} \\
\hline 1200 UTC 5 Sep-0000 UTC 7 Sep & 16 & $30 / 86$ & 16 & $30 / 86$ & Shear increased with time \\
\hline 0000 UTC 9 Sep-0000 UTC 12 Sep & 30 & $35 / 44$ & 11 & $35 / 37$ & SST around $26^{\circ} \mathrm{C}$ \\
\hline 1200 UTC 12 Sep-0000 UTC 15 Sep & 26 & $36 / 53$ & 3 & $38 / 53$ & $\begin{array}{l}\mathrm{SST} \text { about } 25.5^{\circ} \mathrm{C} \text {; limited time } \\
\text { for development }\end{array}$ \\
\hline 1200 UTC 20 Sep-0000 UTC 22 Sep & 22 & $27 / 56$ & 8 & $26 / 61$ & $\begin{array}{l}\text { Relative humidity from } 900-600 \\
\text { hPa averaged } 60 \%-70 \%\end{array}$ \\
\hline 0000 UTC 30 Sep-1200 UTC 2 Oct & 11 & $24 / 77$ & 10 & $24 / 77$ & $\begin{array}{l}\text { Shear increased with time; later } \\
\text { decreased with storm over cool } \\
\text { water }\end{array}$ \\
\hline 1200 UTC 23 Oct-1200 UTC 24 Oct & 30 & $32 / 57$ & 30 & $32 / 57$ & Shear steady with time \\
\hline 0000 UTC 25 Oct-0000 UTC 28 Oct & 28 & $24 / 73$ & 8 & $29 / 72$ & $\begin{array}{l}\mathrm{SST}<26^{\circ} \mathrm{C} \text { when shear de- } \\
\text { creased }\end{array}$ \\
\hline \multicolumn{6}{|l|}{2001} \\
\hline 0000 UTC 16 Sep-1200 UTC 17 Sep & 29 & $36 / 60$ & 28 & $37 / 56$ & \\
\hline 0000 UTC 27 Sep-1200 UTC 30 Sep & 18 & $25 / 90$ & 18 & $25 / 90$ & Shear increased with time \\
\hline 0000 UTC 1 Oct-1200 UTC 2 Oct & $6-20$ & $21 / 80$ & 6 & $21 / 80$ & $\begin{array}{l}\text { Shear increased to } 20 \mathrm{~m} \mathrm{~s}^{-1} \text {, then } \\
\text { decreased; strong deformation }\end{array}$ \\
\hline 1200 UTC 22 Oct-0000 UTC 24 Oct & 20 & $26 / 87$ & 14 & $31 / 76$ & \\
\hline 1200 UTC 4 Nov-0000 UTC 9 Nov & 42 & $30 / 37$ & 6 & $28 / 33$ & SST $25-25.5^{\circ} \mathrm{C}$ \\
\hline 0000 UTC 9 Nov-1200 UTC 11 Nov & 30 & $26 / 45$ & 30 & $26 / 45$ & $\begin{array}{l}\text { Shear decreases when storm over } \\
\text { cool water; deformation }>5 \\
\times 10^{-5} \mathrm{~s}^{-1}\end{array}$ \\
\hline 1200 UTC 14 Nov-1200 UTC 20 Nov & 40 & $28 / 79$ & 32 & $29 / 76$ & Multiple, short-wave troughs \\
\hline
\end{tabular}




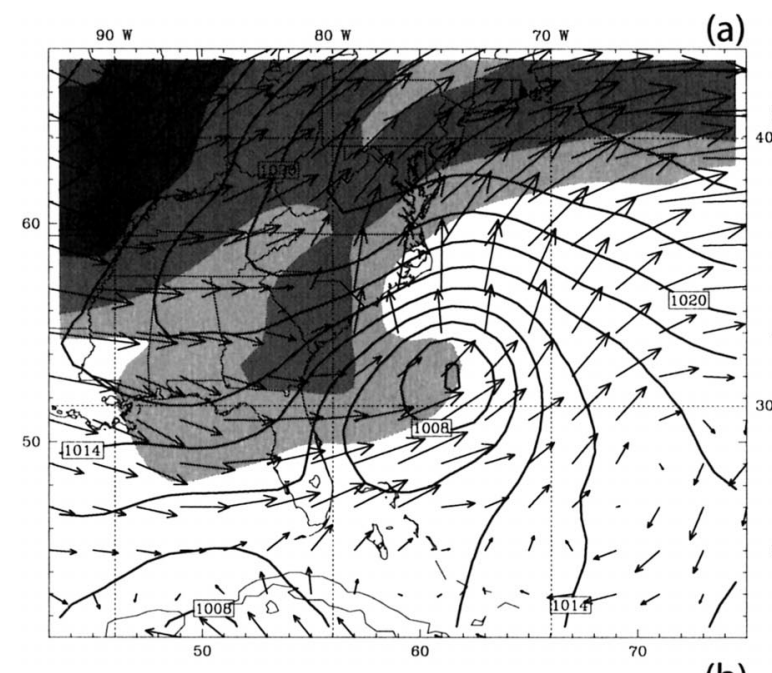

(a)

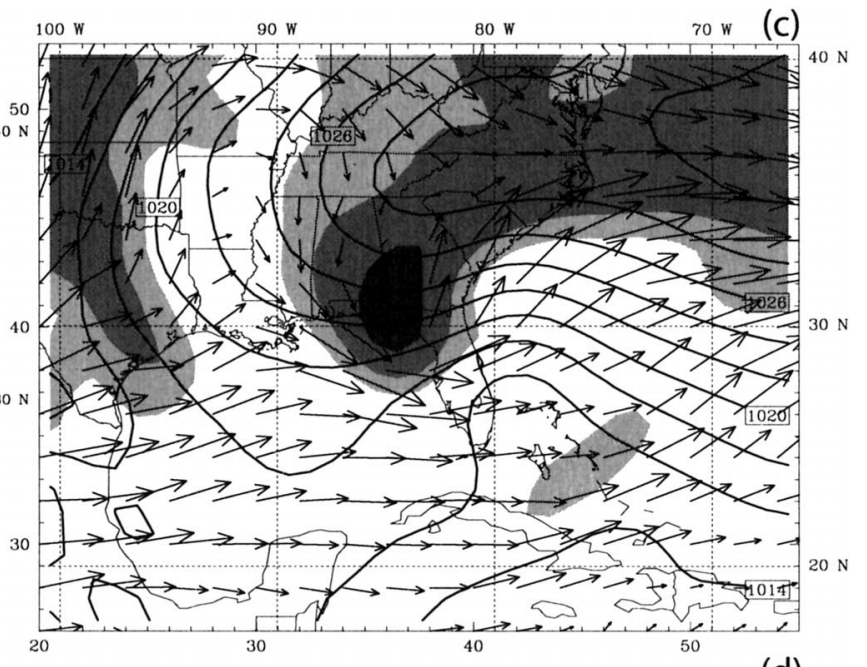

(b)

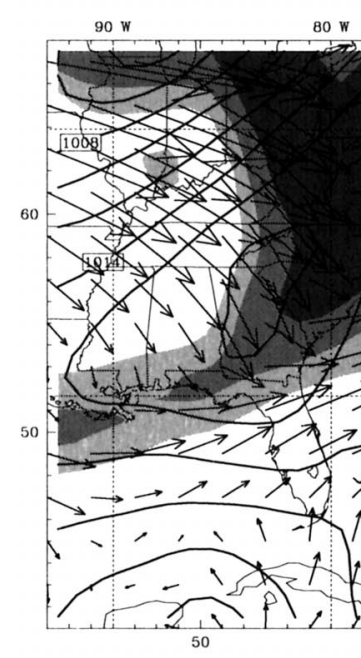

$80 \mathrm{~W}$

$70 \mathrm{w}$

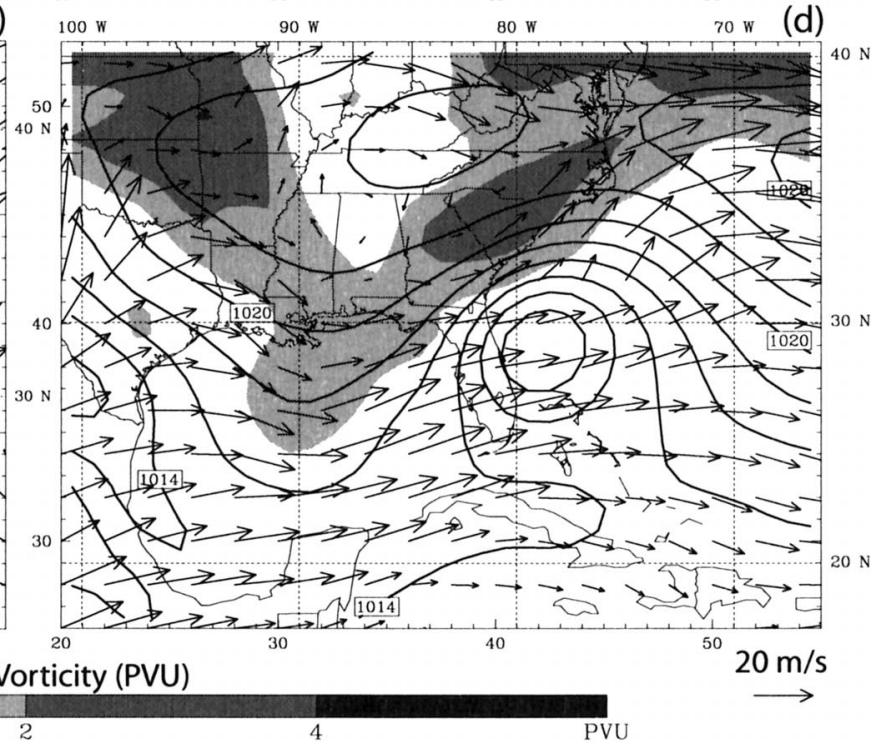

FIG. 3. Sea level pressure (2-hPa interval), 340-K PV, and 340-K wind from AVN analyses valid (a) 1200 UTC 1 Oct and (b) 1200 UTC 2 Oct 2000; and (c) 1200 UTC 14 Nov and (d) 1200 UTC 15 Nov 2001.

ticity advection at $300 \mathrm{hPa}$, averaged over a $7 \times 7$ gridpoint box centered one grid point north and west of the surface cyclone center (Fig. 4a). The box was shifted relative to the center to emphasize troughs approaching within the northwest quadrant of the cyclone (positive values in Fig. 4 corresponding to positive vorticity tendency). We expect the approach of a trough on the northwest flank of a cyclone to increase the vertical wind shear over the center. Such a relationship between potential vorticity anomaly (PVA) and shear is not obvious from Fig. 4, at least on timescales less than $24 \mathrm{~h}$, perhaps owing to the importance of diabatic effects that decrease the vorticity in the upper troposphere. However, when viewed on longer timescales (1-2 d), the temporal envelope of strong shear corresponds well with the successive approach of the two troughs.

The case of 14-20 November 2001 (Figs. 3c,d and Fig. 4b) was also characterized by multiple short-wave troughs affecting a developing surface cyclone. A modest, subsynoptic-scale baroclinic development occurred in response to the approach of trough 1 toward a surface cyclone over the Gulf Stream to the east of Florida. However, as the cyclone was occluding, trough 2 approached and distorted the structure of the incipient baroclinic disturbance, maintaining the shear over the lowlevel center (Figs. 3d and 4b). Less than one day later, trough 3 approached in northwesterly flow and again disrupted the baroclinic cyclone equilibration and increased the shear (Fig. 4b).

Among the nontransitioning cases in which the vertical shear did weaken substantially, but not until the storm was over cooler water, was the subtropical storm of October 2000 (ST). The ST formed roughly one week after Michael and in nearly the same location (Fig. 5). The overall paths of the storms were similar, however, ST moved poleward much faster than Michael, equa- 

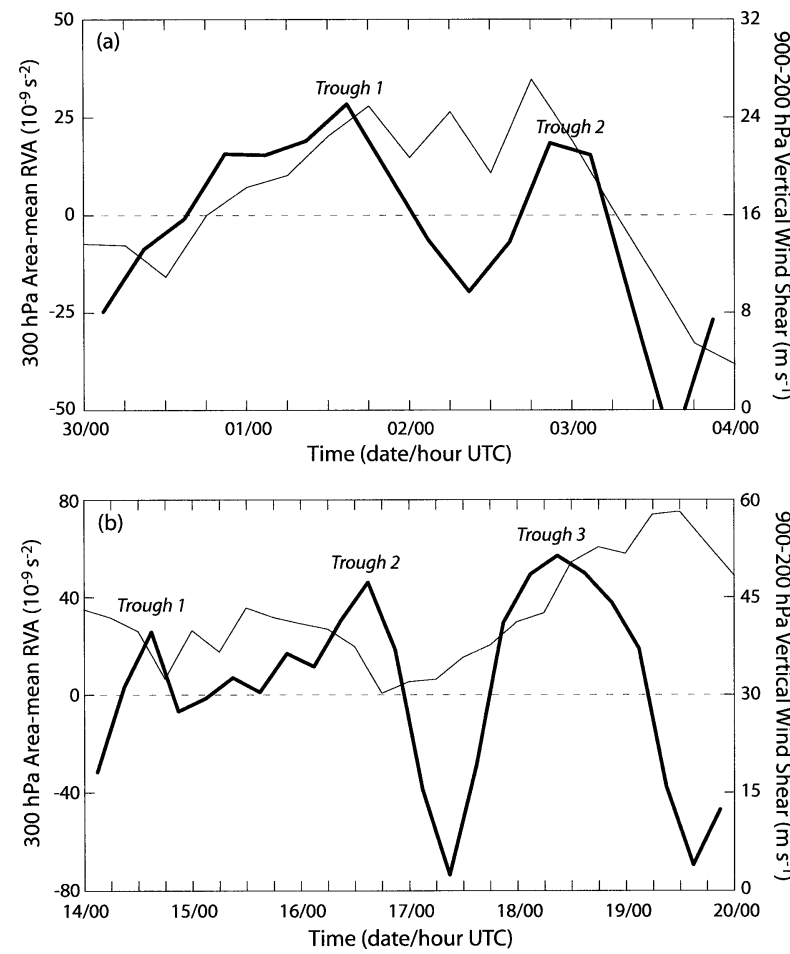

FIG. 4. Time series of vertical shear between 900 and $200 \mathrm{hPa}$ averaged over a $5 \times 5$ box centered on the storm expressed as a velocity difference ( $\mathrm{m} \mathrm{s}^{-1}$, thin line), and the negative of the relative vorticity advection at $300 \mathrm{hPa}$ averaged over a $7 \times 7$ box offset one grid point north and west from the storm center $\left(10^{-9} \mathrm{~s}^{-2}\right.$, heavy line) for (a) 30 Sep-4 Oct 2000 and (b) 14-20 Nov 2001.

torward of about $35^{\circ} \mathrm{N}$. The similar tracks imply that both storms moved over similar ocean temperatures, at least early in their developments. However, the more rapid poleward translation of ST placed it over cool water by the time the vertical shear decreased (Fig. 6).

A comparison of the upper-level $\mathrm{PV}$ and $900-\mathrm{hPa}$ potential temperature at 0000 UTC 27 October (Fig. 7a) with that present during the baroclinic development preceding Michael (Fig. 1a) reveals marked differences. Cyclonic wrapping, reminiscent of the LC2 paradigm of Thorncroft et al. (1993) characterized ST, whereas filamentation and the formation of a cutoff low characterized the pre-Michael disturbance (the LC1 paradigm). Further examination of the LC1 life cycle in Thorncroft and Hoskins (1990) reveals the occurrence of frontal cyclogenesis on a subsynoptic scale at a relatively low latitude following the formation of a cutoff low in the upper troposphere (see Figs. 4-5 of Thorncroft and Hoskins 1990). The structure of this secondary cyclone is remarkably similar to the structure of the preMichael storm.

To quantify the differences of upper-level PV structure on storm motion, we performed PV inversion techniques following Davis and Emanuel (1991) using the NCEP global analyses. We calculated the contribution of PV anomalies (defined as departures from a centered,

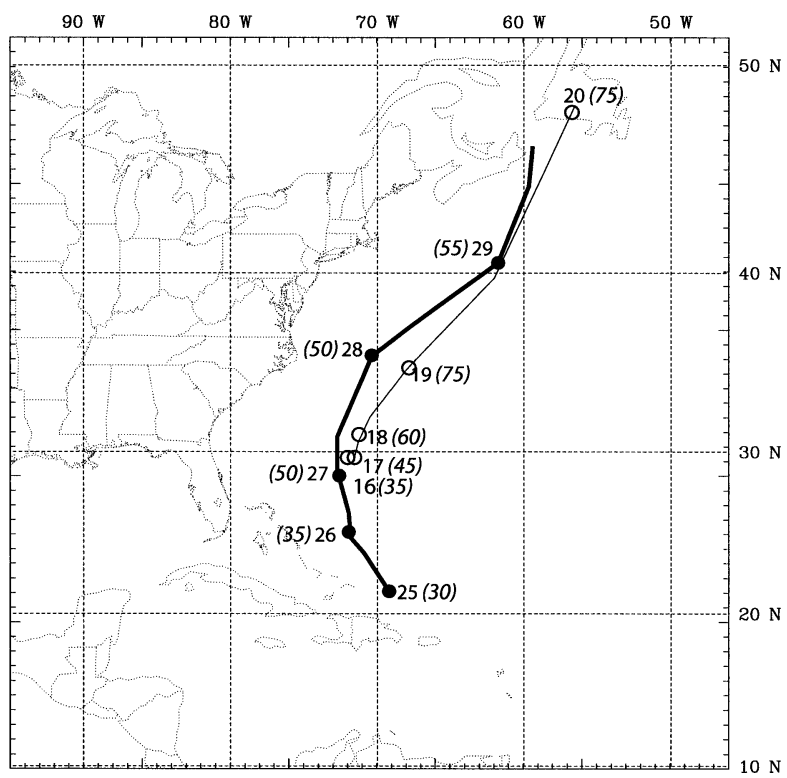

FIG. 5. Tracks of Michael (thin line) and ST (heavy line) taken from best track data. Michael (open circles) and ST (dots) indicate 0000 UTC positions on the dates shown. Maximum sustained winds (kt) are indicated in parentheses.

8-day mean) in the layer from 500 and $200 \mathrm{hPa}$ to the deep-layer, density-weighted mean wind averaged between 900 and $500 \mathrm{hPa}$. The 900-500-hPa layer-mean wind represented the steering flow better than the traditionally used 900-200-hPa layer, presumably because the disturbances in question were baroclinic. Comparing the steering flows, averaged about a $5^{\circ}$ by $5^{\circ}$ box centered on the storm, at 0000 UTC 16 October (pre-Michael) and 0000 UTC 27 October (ST) revealed a vector difference (ST minus pre-Michael) of $8 \mathrm{~m} \mathrm{~s}^{-1}$ directed

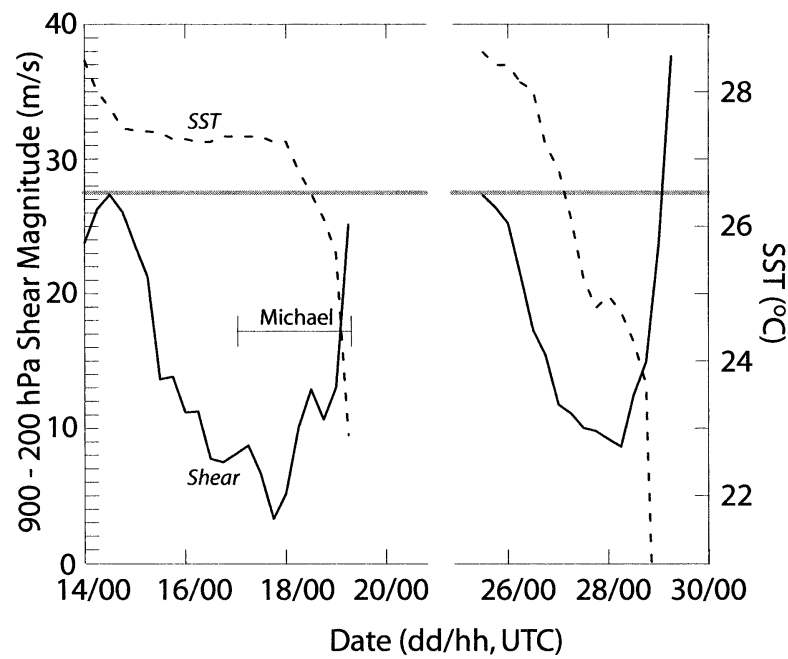

FIG. 6. Time series of storm-centered, 900-200-hPa wind shear and SST (from AVN analyses) for (left) the pre-Michael disturbance and Hurricane Michael and (right) the subtropical storm of Oct 2000 ST. The tropical phase of Michael is indicated. 

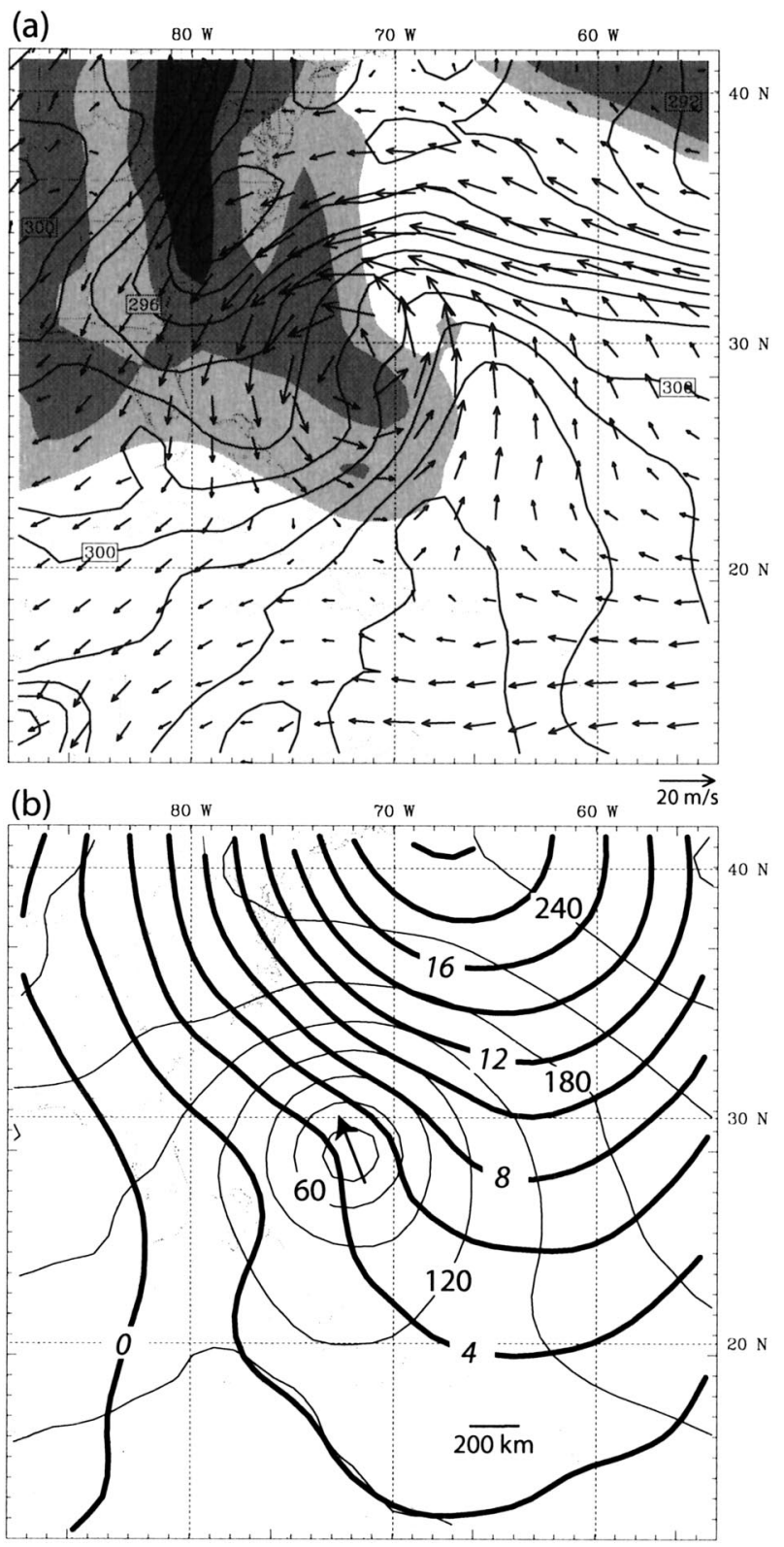

FIG. 7. (a) Wind and temperature (1-K interval) at $900 \mathrm{hPa}$ and 340-K PV from AVN analyses valid 0000 UTC 27 Oct 2000 (ST); (b) geopotential height at $1000 \mathrm{hPa}$ [contour interval (c.i.) $=30 \mathrm{~m}$ ] and layer-mean streamfunction $(900-500 \mathrm{hPa}$ ) anomaly associated with deviation of PV from an 8-day centered mean (c.i. $=2 \times 10^{6}$ $\mathrm{m}^{2} \mathrm{~s}^{-1}$ ). See text for further explanation. (b) The arrow indicates the local nondivergent wind direction over the storm center (magnitude about $8 \mathrm{~m} \mathrm{~s}^{-1}$ ). A streamfunction gradient of $2 \times 10^{6} \mathrm{~m}^{2} \mathrm{~s}^{-1}$ over $200 \mathrm{~km}$ (see scale) yields a nondivergent wind speed of $10 \mathrm{~m} \mathrm{~s}^{-1}$.

poleward. This difference resulted from a deep southsoutheasterly flow directed across the cyclone in ST (Fig. 7b) and almost no steering flow in the case of Michael (not shown). The observed motion of ST was about $5 \mathrm{~m} \mathrm{~s}^{-1}$ toward the north at this time, compared to the nearly stationary pre-Michael disturbance. Thus, we conclude that the differences in upper-tropospheric synoptic-scale structure were responsible for moving the subtropical over cooler water before it could transform into a tropical cyclone.

\section{c. Synthesis of results using global analyses}

Overall, it appears that the cases in which baroclinic development is allowed to proceed to its equilibrated (i.e., occluded) state while the storm remains over warm water (SST $>26^{\circ} \mathrm{C}$ or so) are the cases in which tropical cyclogenesis occurs. We use the term equilibration to mean the elimination of the systematic tropopause PV gradient in the vicinity of the cyclone such that further baroclinic growth is meager. Multiple trough interactions, unless the last in the series of troughs has the greatest amplitude, are not generally favorable if their spacing is too close temporally relative to the timescale of equilibration.

The central question appears to be "how does the shear decrease"? In general, there is no mystery because it is well known that occlusion tends toward an equivalent barotropic structure in which the vertical shear over the center is small (Palmén and Newton 1969). Unless the baroclinic cyclone is embedded within strong horizontal deformation, or, as seen earlier, if there are multiple interactions with upper-tropospheric troughs, it will reach some form of occluded state with weak shear above the center. However, time is usually limited for the occlusion to take place, given that the region of sufficiently warm ocean temperatures is limited, especially late in the Atlantic tropical cyclone season, and the poleward translation speed is often nontrivial. Thus, rapid occlusion would facilitate the production of a favorable, low-shear environment while the primary storm is still over warm water. As we will demonstrate for Michael in 2000 the rapid reduction in shear is facilitated by diabatic heating and its secondary circulation.

Cases such as Humberto in 2001 are characterized by exceedingly weak baroclinic development, to the point where the classical meaning of occlusion may not apply. In these cases, we hypothesize that it is the convection organized by the synoptic scale that is responsible for the decrease in shear. Thus, an intermediate step of convective organization is required to link the synopticscale precursor with the incipient mesoscale vortex capable of self-amplification through air-sea interaction. This sequence of events characterizes well the development of Diana in 1984 (Davis and Bosart 2001, 2002; Powers and Davis 2002).

In the remainder of the paper, we will concentrate on Michael and perform simulations to better understand how the vertical shear is reduced and how the transition from cold-core to warm-core cyclone takes place.

\section{Michael in 2000}

\section{a. Observations}

Hurricane Michael was first analyzed by the Tropical Prediction Center (TPC) around 0000 UTC 17 October, 

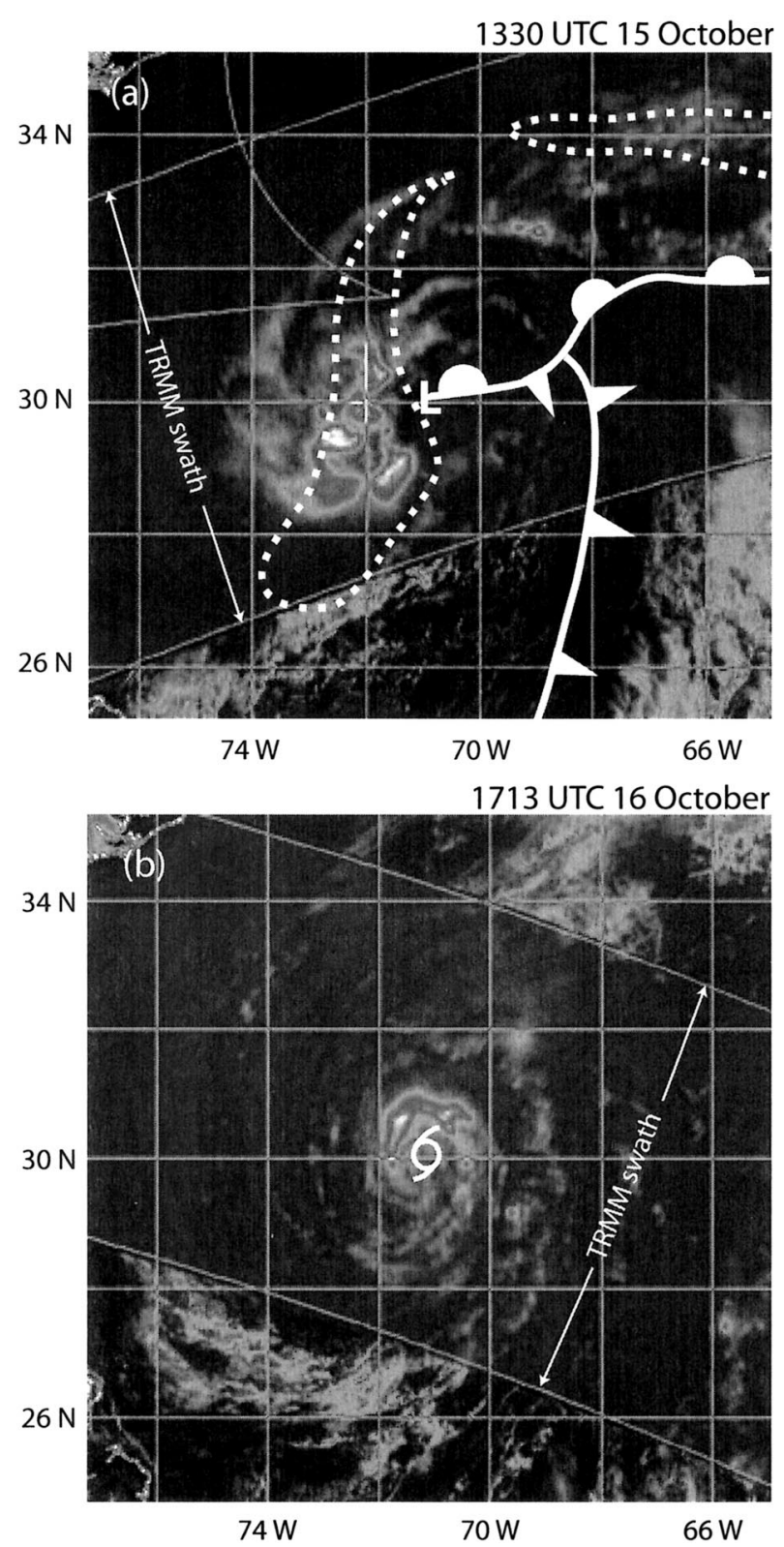

FIG. 8. Gray-scaled images from TRMM composites at (a) 1330 UTC 15 Oct and (b) 1713 UTC 16 Oct 2000. Peak rain rates (white) derived from TRMM exceed $25 \mathrm{~mm} \mathrm{~h}^{-1}$. Frontal symbols are annotated at the earlier time. The dotted line in (a) is the $80 \%$ relative humidity contour derived from the 700-hPa AVN analysis for 1200 UTC 15 Oct. The tropical storm symbol is shown at the center in (b) even though Michael was not officially a tropical storm until after 0000 UTC 17 Oct.

having previously existed as a baroclinic cyclone developing along a relatively strong frontal boundary during the previous 4 days. Development was induced by an upper-tropospheric cyclonic vortex that had separated from the main westerlies farther north (Fig. 1a). The initial development revealed some similarity to the baroclinic phase preceding Hurricane Diana in 1984. In the present case, the deep-layer vertical shear was about twice as strong as prior to Diana and the baroclinic cyclone prior to Michael was also stronger.

Examination of satellite data, especially data from the Tropical Rainfall Measuring Mission (TRMM) instrument, suggested that Michael actually became a tropical cyclone well before its alleged transition on 17 October. Figure 8 depicts TRMM radar images at 1330 UTC 15 October and 1713 UTC 16 October. The position of the surface low at 1330 UTC 15 October (Fig. 8a) was estimated based on animations of low cloud motion and was about $200 \mathrm{~km}$ to the east of the precipitation shield. This structure was evidence that the cyclone was still baroclinic at this time, consistent with the frontal structure subjectively inferred from the NCEP analysis at 1200 UTC 15 October.

By 1713 UTC 16 October, a markedly different structure was evident. Spiral bands of precipitation encircled the storm, and heavy rainfall was found within a partial ring about $70-80 \mathrm{~km}$ from the estimated storm center (Fig. 8b). The heavy rainfall was probably part of a developing eyewall and suggested a storm of at least tropical storm intensity. This rainband formed from deep convection that developed explosively around 1200 UTC on the east and north sides of the storm.

Around the time of the image shown in Fig. 8b, the best track estimate of maximum surface wind speed was about $15 \mathrm{~m} \mathrm{~s}^{-1}$. Unfortunately (for our analysis), the rather intense baroclinic cyclogenesis on 14 and 15 October caused a near absence of ship data near the developing storm. Surface winds estimated by the National Aeronautics and Space Administration Jet Propulsion Laboratory (NASA JPL) SeaWinds instrument aboard NASA's Quick Scatterometer (QuikSCAT) were available at 0917 UTC and 2318 UTC 15 October, and 1032 UTC and 2253 UTC 16 October. (See http://manati. wwb.noaa.gov/quikscat to access historical images.) On 15 October, as suggested in Fig. 8a, the storm was clearly extratropical, and the strongest surface winds, up to $35 \mathrm{kt}$, occurred in the northwest quadrant of the storm (not shown). On 16 October, many of the wind estimates near the storm center were flagged for possible rain contamination. Among these were a 40-kt wind at 1032 UTC and numerous 35-40-knot winds at 2253 UTC. The strongest wind not potentially contaminated by rain was $35 \mathrm{kt}$ at the later time and was about $100 \mathrm{~km}$ from the estimated center. Given that the horizontal resolution of the QuikSCAT winds is similar to the scale of the developing eyewall apparent in the TRMM data, and that backscatter measurements underestimate wind speeds near $20 \mathrm{~m} \mathrm{~s}^{-1}$ and greater (Donnelly et al. 1999), the QuikSCAT winds are probably conservative estimates of the true maximum winds. Therefore, it is likely that Tropical Storm Michael was born during the morning of 16 October, perhaps 6-12 h earlier than the official estimate.

\section{b. Simulations}

The MM5 simulations of Michael discussed herein were initialized at 0000 UTC 15 October. The initial 


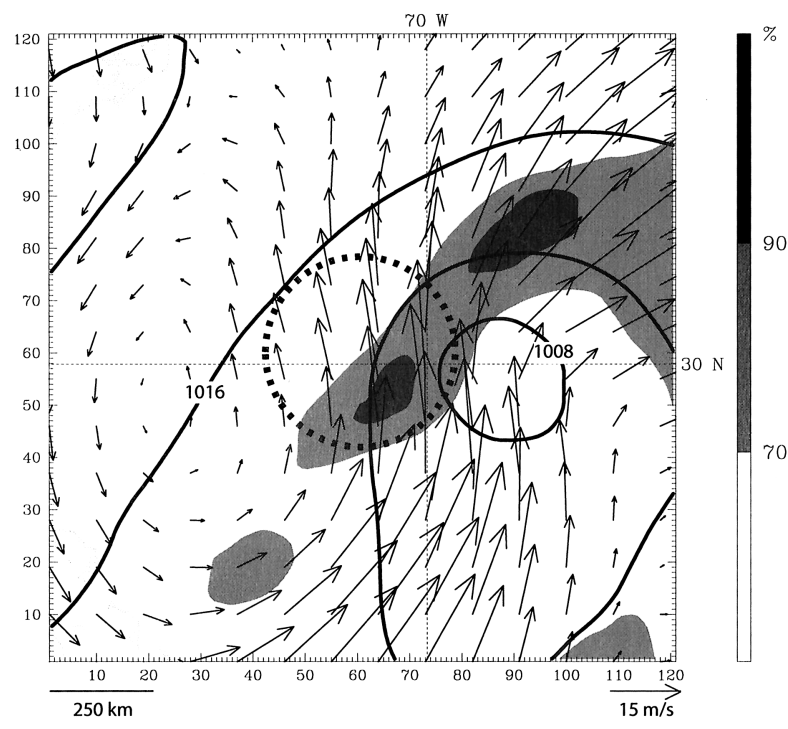

FIG. 9. Sea level pressure (c.i. $=4 \mathrm{hPa}), 700-\mathrm{hPa}$ relative humidity (medium gray $\equiv \mathrm{RH}>70 \%$; dark gray $\equiv \mathrm{RH}>90 \%$ ) and $900-$ 200 -hPa shear vectors valid 0000 UTC 15 Oct 2000, the initialization time for the Michael simulation (control). All of domain 3 is shown. Heavy dotted circle indicates boundary of SST perturbation less than $-1 \mathrm{~K}$ for perturbed SST simulation.

condition is shown in Fig. 9. Henceforth all results will be shown on domain $3(121 \times 121$ points, $12.3 \mathrm{~km}$ grid spacing). The surface cyclone was located about 400 $\mathrm{km}$ to the west of a thermal ridge (denoted by the anticyclonic curvature of the shear vector in Fig. 9) and in a region of strong shear through the troposphere.

Thirteen hours into the simulation, the model rainfall pattern broadly matched that seen from TRMM (cf. Figs. $8 \mathrm{a}$ and 10a), with most of the rainfall on the west side of a still-extratropical storm. Note that MM5 accentuated a nearly east-west precipitation band to the southwest of the surface cyclone. There was some evidence of a sharp, east-west-oriented southern edge of the precipitation in the TRMM data at nearly the same time. Note also that the model correctly simulated a "dry slot" to the east of the surface cyclone, with lighter rain in an arc to the north of the storm.

By 1700 UTC 16 October (Fig. 10b), a complete transformation of the cyclone structure has occurred in the simulation. As in the TRMM data, a partial eyewall has formed. The simulated cyclone central pressure was about $980 \mathrm{hPa}$ and the maximum sustained near-surface winds were approaching $30 \mathrm{~m} \mathrm{~s}^{-1}$ (Fig. 11b). By this time, the highly asymmetric, baroclinic structure had been replaced by a more symmetric, tropical cyclone.

Time series (Fig. 11) reveal that, like the case of Diana in 1984 (Davis and Bosart 2001) the development occurred in three stages. Following the initial intensification of a baroclinic cyclone, ending at roughly 1600 UTC 15 October, there was a 6-h period of quiescence until 2200 UTC 15 October during which the near-surface wind and sea level pressure did not signify intensity
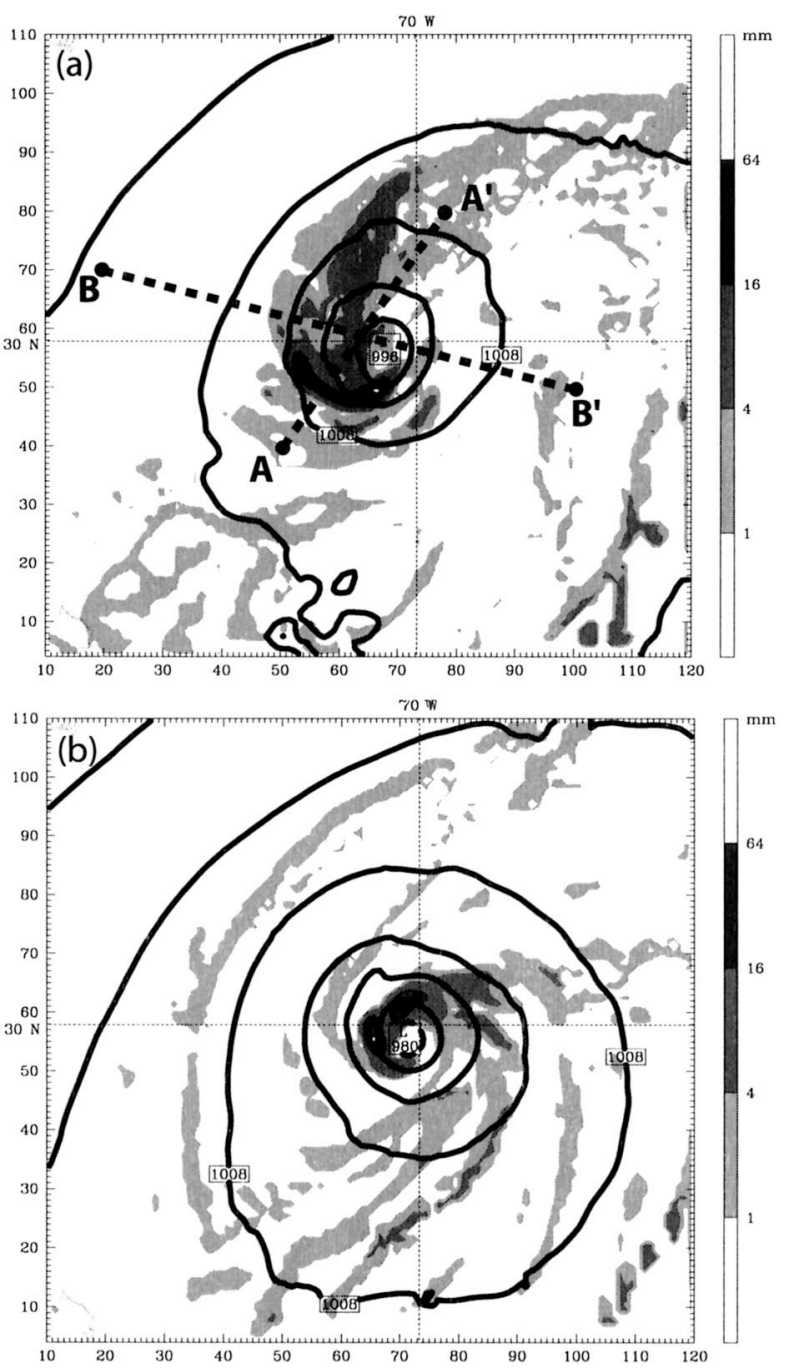

FIG. 10. Sea level pressure (4-hPa interval, except 8-hPa interval for pressures less than $1000 \mathrm{hPa}$ ) and hourly rainfall $(\mathrm{mm})$ from the control simulation valid (a) 1300 UTC 15 Oct and (b) 1700 UTC 16 Oct. Heavy dashed lines in (a) denote location of cross sections A$\mathrm{A}^{\prime}$ (Fig. 13) and B-B' (Fig. 16).

change. However, during this period the vertical shear continued to decrease from about 13 to about $9 \mathrm{~m} \mathrm{~s}^{-1}$. Beginning around 2200 UTC 15 October, a new period of development occurred, ending around 1800 UTC 16 October as the vertical shear increased slightly in response to an approaching weak upper-tropospheric trough.

While the structure of the simulated storm and the timing of its apparent transition to a tropical storm roughly correspond to observations, it is difficult to support the intensity revealed by the simulation on 16 October from the limited observations available. As shown in Fig. 11b, maximum winds derived from QuikSCAT remained nearly $20 \mathrm{~m} \mathrm{~s}^{-1}$ for the entire period of the simulation, suggesting that the control simulation intensified the storm too rapidly after 2200 UTC 15 Oc- 

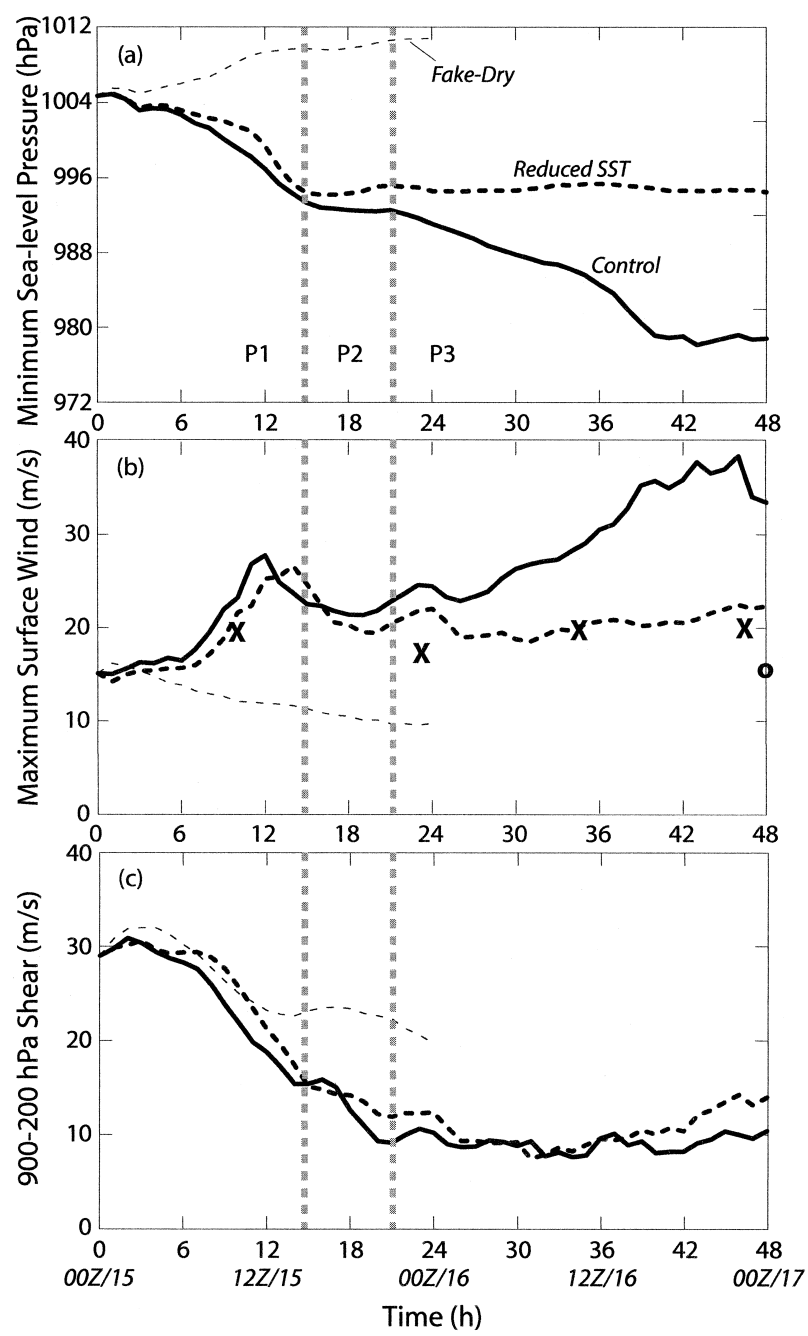

FIG. 11. Time series of (a) minimum central sea level pressure; (b) maximum sustained near-surface wind; and (c) 900-200-hPa vertical shear. The shear was averaged over a $25 \times 25$ gridpoint box $(308$ $\mathrm{km} \times 308 \mathrm{~km}$ ) centered on the storm. Observations are denoted by Xs for QuikSCAT data (discussed in section 4a) and Os for best track data obtained from the National Hurricane Center (beginning 0000 UTC 17 Oct.) Vertical dashed gray lines separate the baroclinic development (P1), quiescent (P2), and tropical (P3) periods.

tober. However, as noted earlier, these observations likely underestimated the true wind speeds (Donnelly et al. 1999).

Although a number of sensitivity simulations were carried out, varying resolution and physics, the greatest departure from the control simulation during the final $24 \mathrm{~h}$ was obtained by reducing the SST by only about $1{ }^{\circ} \mathrm{C}$ underneath the storm. MM5 allows a time-varying SST, but does not directly incorporate the effect of storm-induced upwelling on the ocean surface temperature. The minimal translation of Michael suggests that upwelling effects could have been important. Given the absence of ships in the region there were few in situ measurements of SST during the period. Satellite estimates were hampered due to persistent, deep cloud cov- er and precipitation. Estimates of ocean surface temperature derived from the Advanced Very High Resolution Radiometer (AVHRR) aboard the NOAA-14 satellite $^{1}$ revealed an approximate decrease in SST by about $2^{\circ}-3^{\circ} \mathrm{C}$ near and slightly poleward of $30^{\circ} \mathrm{N}, 70^{\circ} \mathrm{W}$ between 10 and 20 October. Although we cannot be certain when the cooling occurred, it is reasonable to assume that the disturbed sea state and persistent cloud, rain, and cooler air temperatures associated with the baroclinic cyclone development could have created a substantial cooling by 15 October.

Therefore, we ran a sensitivity simulation in which we cooled the SST by a maximum of $1.5^{\circ} \mathrm{C}$ with a Gaussian radial decay over a length scale of $400 \mathrm{~km}$ centered roughly on the position of the pre-Michael disturbance at 1200 UTC 15 October (see Fig. 9), slightly to the west of the initial storm location at 0000 UTC 15 October. This subtle cooling resulted in a nearly complete removal of the second intensification phase noted in the control simulation. It also brought the maximum winds into much closer agreement with the QuikSCAT data. Given the probable underestimate of winds from QuikSCAT, we are fairly confident that the control and reduced-SST simulations bracketed the true storm intensity.

We interpret the difference between the modified SST and control simulations as indicative of a removal of air-sea interaction feedback in the former as the SST underneath the storm decreased from just over $27^{\circ}$ to around $26^{\circ} \mathrm{C}$. Such a large sensitivity to SST beneath the storm is fully consistent with the results of published studies (e.g., Schade 2000). As the primary emphasis in the present paper is the conditioning of the atmosphere for tropical cyclogenesis, more than the actual tropical cyclogenesis phase, we note that the initial 24 $\mathrm{h}$ proceeded very much the same as in the control simulation. We conclude that the uncertainty in SST is responsible for a difference that is larger than the apparent discrepancy between the control simulation and observations. Therefore, we will not focus extensively on the last 18-24 $\mathrm{h}$ of the simulation, but rather emphasize the transition in structure that occurred during the first 24$30 \mathrm{~h}$.

Time-radius representations of kinematic and thermodynamic quantities (Fig. 12), support the assertion that the initial development in the control simulation was baroclinic and cold core, while the later development was tropical and warm core. An important aspect of the initial baroclinic development was a decrease in the radius of maximum wind (RMW) from roughly 200 to $100 \mathrm{~km}$. This occurred as maximum near-surface

\footnotetext{
${ }^{1}$ Images were obtained from Rutgers University at http://marine. rutgers.edu/mrs/newevery.topex.html. Information on the processing of AVHRR data may be found at http://fermi.jhuapl.edu/avhrr/primer/ primer_html.html, a World Wide Web site created by Dr. Frank Manaldo at the Applied Physics Laboratory at The Johns Hopkins University.
} 

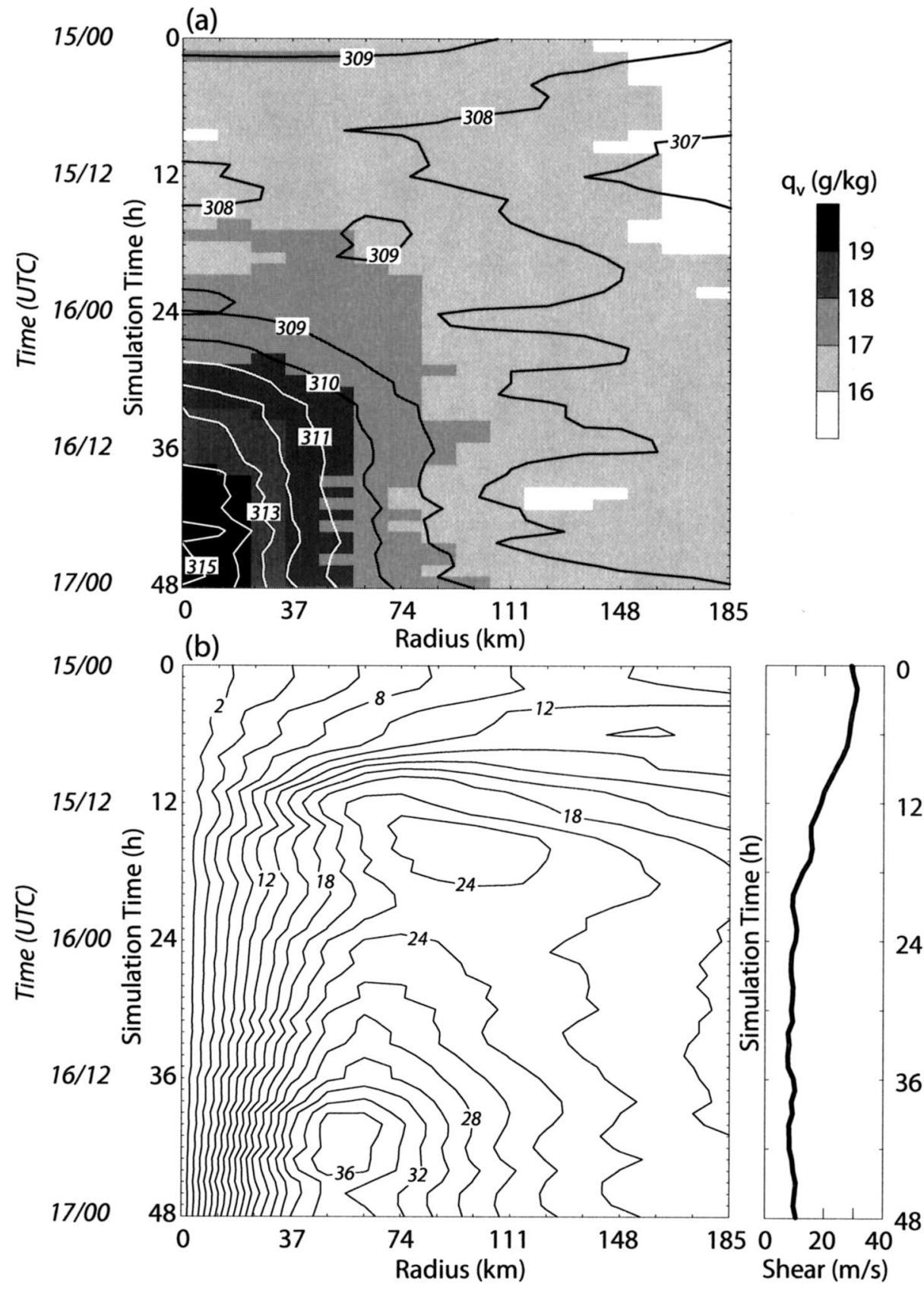

FIG. 12. Time-radius diagrams from the control simulation of (a) azimuthal and layer (roughly 850$700 \mathrm{hPa}$ ) mean potential temperature and azimuthal mean of water vapor mixing ratio averaged over the lowest five model levels (shaded); and (b) maximum azimuthal mean tangential wind at about 500 $\mathrm{m}$ AGL. (bottom right) The time series of vertical wind shear adapted from Fig. 11. The time axis is labeled as both time during the control simulation (h) and universal time (date/hour UTC).

winds increased to nearly $25 \mathrm{~m} \mathrm{~s}^{-1}$ around $1200 \mathrm{UTC}$ 15 October (see Fig. 11b).

The warm core formed after the quiescent period (cf. Figs. 12a and 12b near 18-24 h). During the quiescent period not only did the vertical shear decrease, but also the boundary layer water vapor began increasing (Fig. 12a). This moistening phase occurred in the simulation of Diana discussed in Davis and Bosart (2001). During the last $24 \mathrm{~h}$ of the simulation (0000 UTC 16 to 0000 UTC 17 October), the RMW decreased further to about $50 \mathrm{~km}$, the warm core strengthened, and the water vapor content of the boundary layer continually increased. It is our assessment that air-sea interaction, in the form of the wind-induced surface heat exchange concept of 
(a)

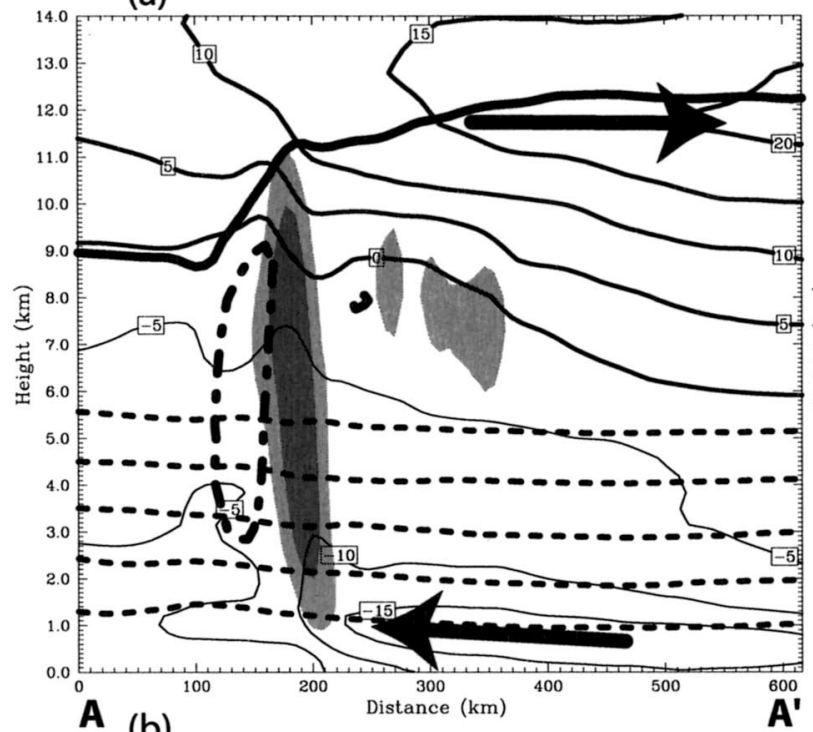

A (b)

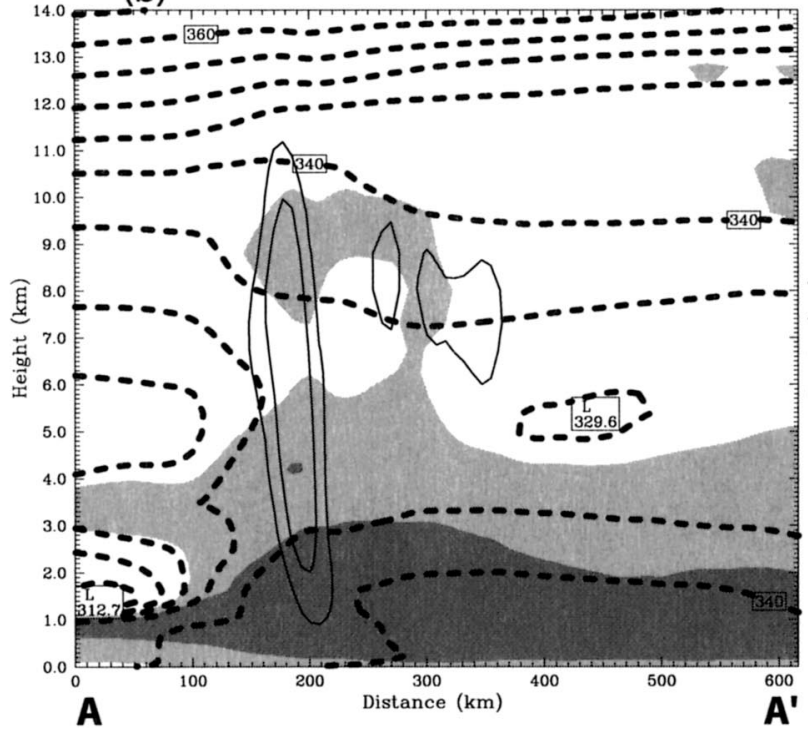

(c)

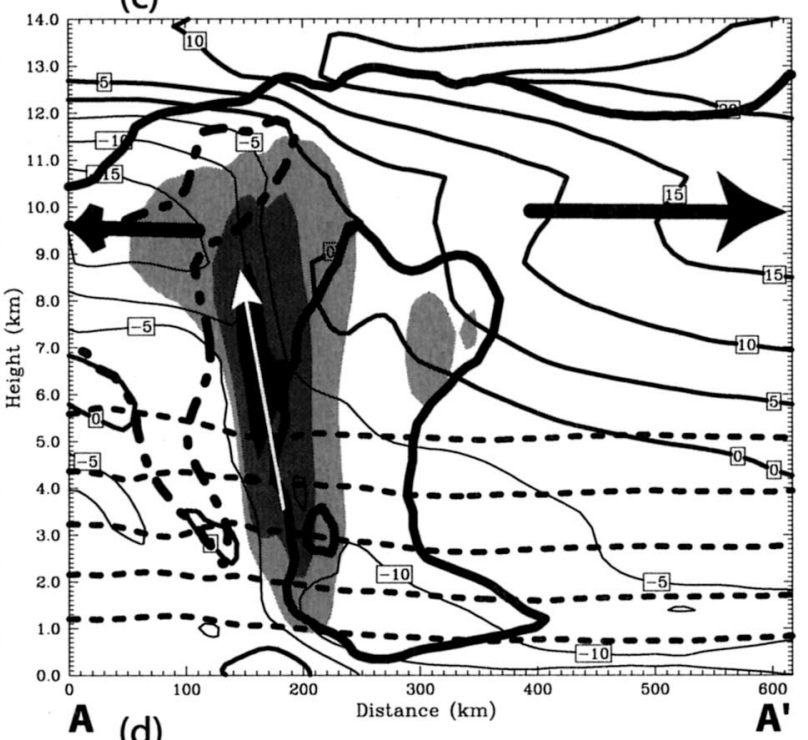

A (d)

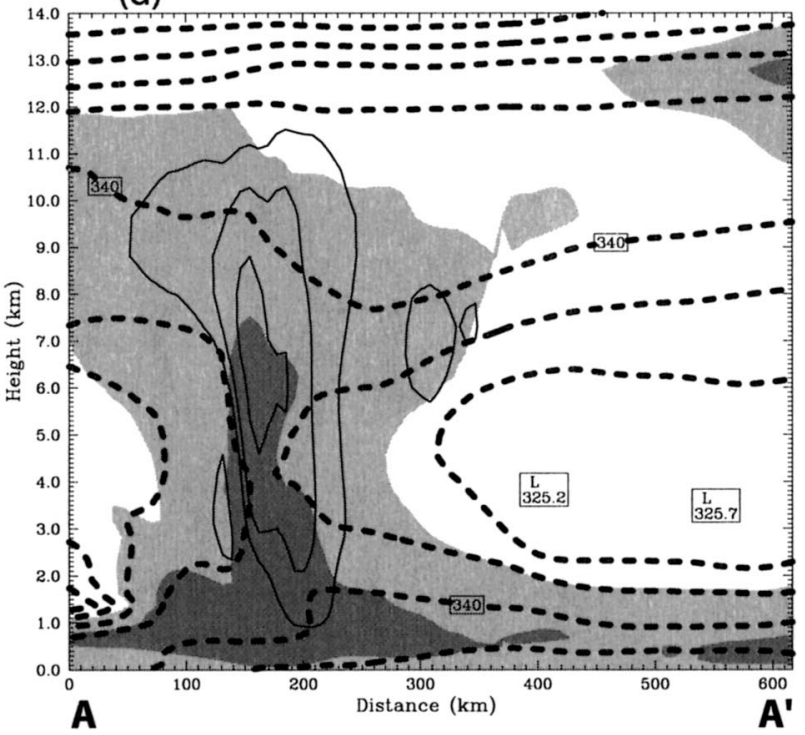

FIG. 13. Cross sections (see Fig. 10 for location) of (a) vertical velocity (light gray $>20 \mathrm{~cm} \mathrm{~s}^{-1}$, medium gray $>40 \mathrm{~cm} \mathrm{~s}^{-1}$, dark gray $>80 \mathrm{~cm} \mathrm{~s}^{-1}$ ), potential temperature (dashed lines, interval $5 \mathrm{~K}$ up to $330 \mathrm{~K}$ ), horizontal wind in the plane of the cross section (thin solid lines for negative values), the 0-PVU contour (heavy dash-dotted line), and the 2-PVU contour (heaviest solid line) all valid at 0600 UTC 15 Oct (6-h forecast); (b) contoured vertical velocity (interval $20 \mathrm{~cm} \mathrm{~s}^{-1}$ ), equivalent potential temperature (dashed, interval $5 \mathrm{~K}$ ), and relative humidity (light gray $>70 \%$, dark gray $>90 \%$. (c),(d) As in (a),(b) but for 1200 UTC 15 Oct (12-h forecast). The bold, black arrows in (a),(c) illustrate schematically the flow in the plane of the cross section. (c) The white arrow illustrates schematically the vorticity vector in the plane of the cross section.

Emanuel (1986, 1995), was operating at that time in the control simulation.

During the mesoscale, baroclinic cyclogenesis period of Michael (prior to 0000 UTC 16 October), the primary region of precipitation was organized along a northsouth-oriented bent-back front (Fig. 10a). However, the southern end of this rainfall featured a mesoscale, eastwest-oriented band of heavy rainfall. A cross section oriented perpendicular to this line (Fig. 13) reveals that the band formed slightly downshear from a tropopause depression, in a region where the tropopause height and tropopause potential temperature exhibited a sharp gradient. Furthermore, ascent of potentially unstable air in the lower troposphere along the gently sloping isentropic surfaces that defined the low-level baroclinity created absolute instability as the air neared saturation.

The convection, although only about $12 \mathrm{~km}$ deep, rapidly intensified and formed a slightly sloped updraft maximizing at about $1 \mathrm{~m} \mathrm{~s}^{-1} .^{2}$ The potential vorticity

${ }^{2}$ Note that the cross section represents a centered average over 20 points in the direction orthogonal to the section. 
$70 \mathrm{~W}$

$10 \mathrm{~h}$
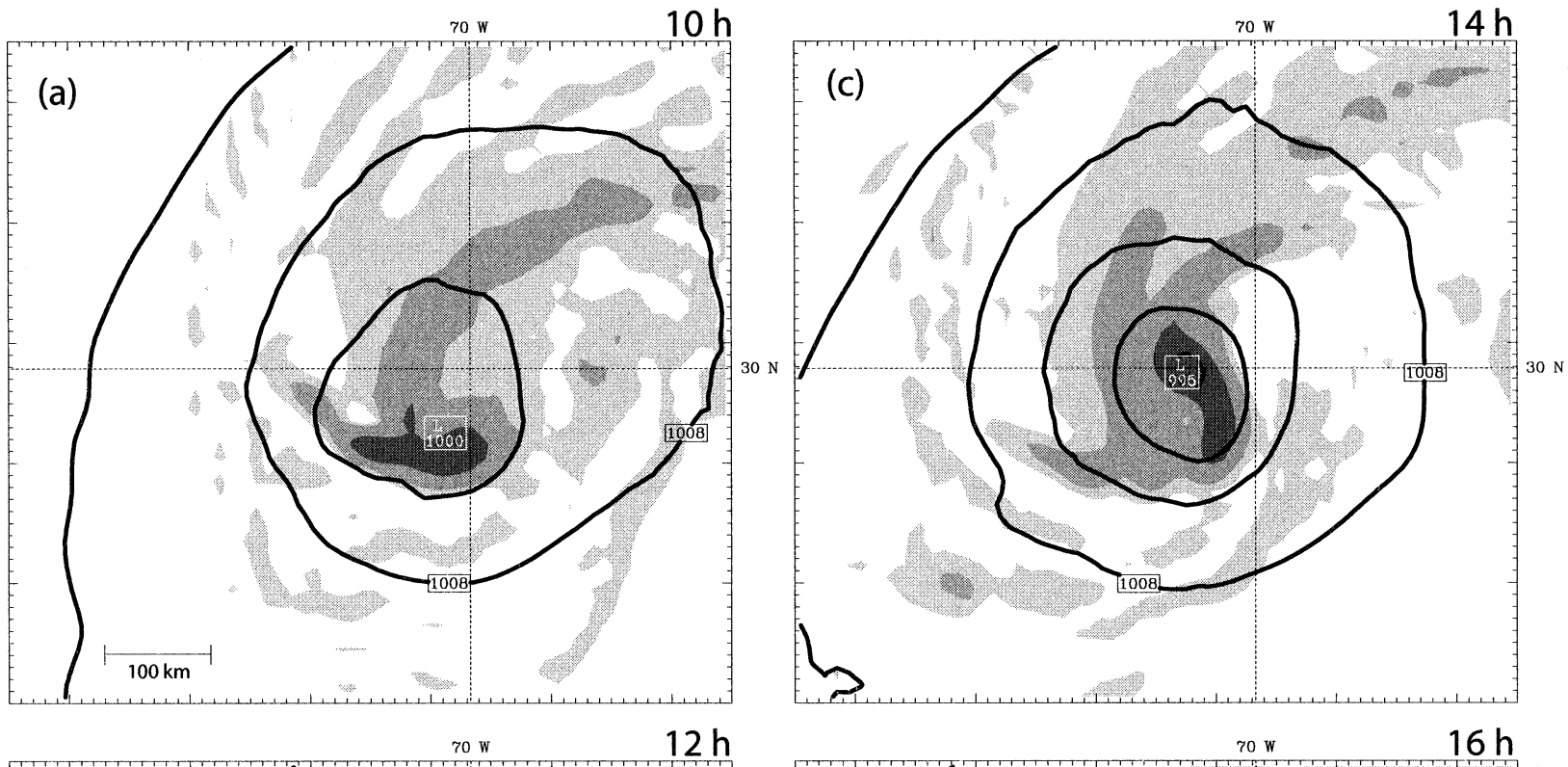

$12 \mathrm{~h}$
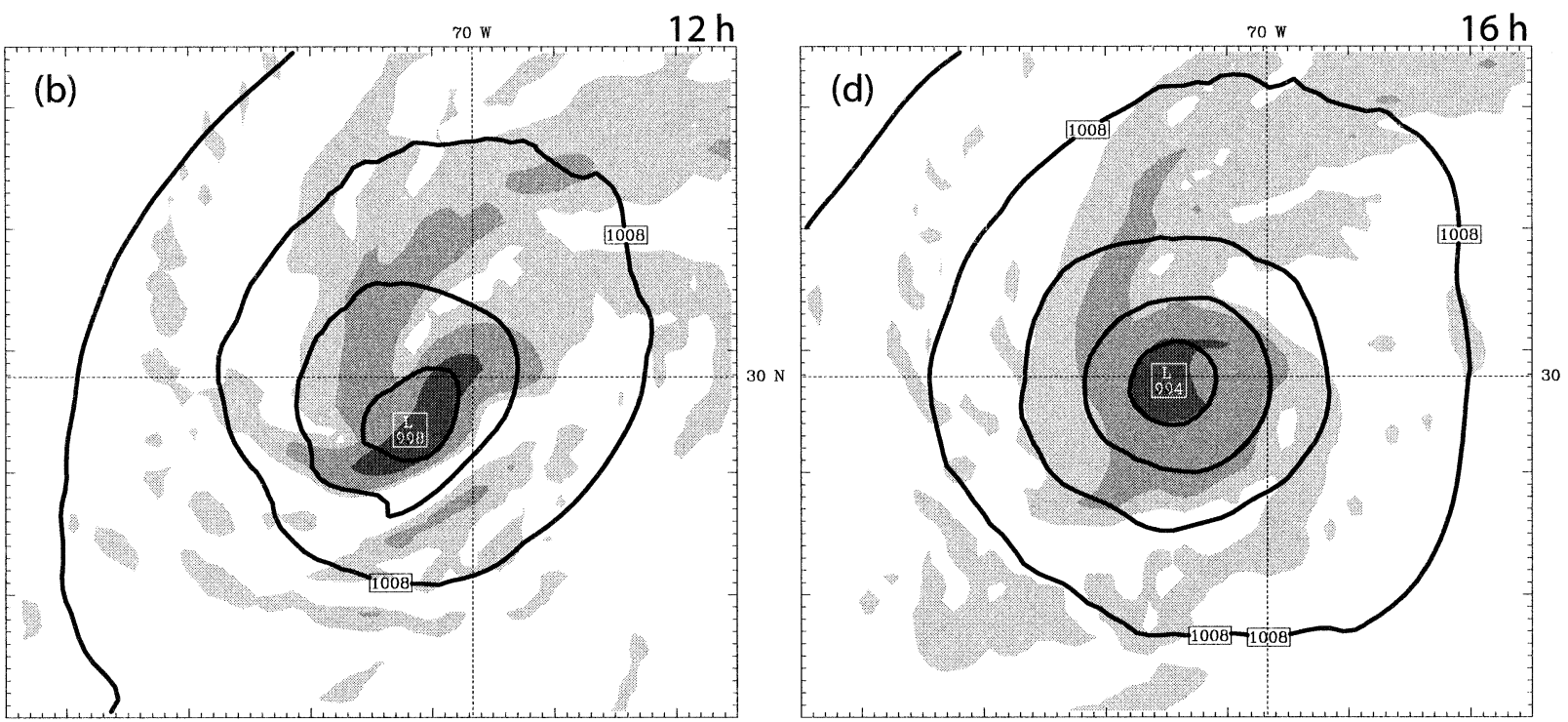

900 hPa Relative Vorticity

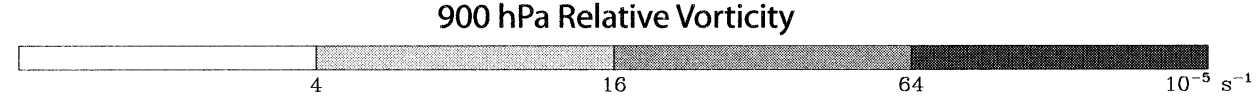

FIG. 14. Relative vorticity (grayscale, units $10^{-5} \mathrm{~s}^{-1}$ ) at $900 \mathrm{hPa}$ and sea level pressure (4-hPa interval) at (a) 1000, (b) 1200, (c) 1400, and (d) 1600 UTC 15 Oct.

also underwent a marked transition (Figs. 13a,c) during which time the tropopause was raised above the convection and the divergent outflow centered 10-11 km above ground level (AGL) advected high PV associated with the tropopause depression southward. The PV in the middle troposphere featured a dipole pattern with negative PV on the south flank of the rainband in the upper troposphere and relatively large PV on the north side, concentrated in the lower troposphere. Because there was positive vertical wind shear normal to the cross section (i.e., flow into the page aloft), the vorticity vector pointed upward and to the left (southwestward).
As demonstrated in Raymond (1992), where the heating increases upward along the vorticity vector, PV increases nonconservatively. Past the heating maximum, where heating decreases along the vorticity vector, PV decreases. This simple argument explains qualitatively the vertical and horizontal redistribution of PV caused by the latent heating. After forming, the high-PV air and associated cyclonic vorticity in the lower troposphere on the north side of the rainband merged with the storm center (Fig. 14). This process resulted in the scale contraction and rapid intensification of the cyclone prior to 0000 UTC 16 October. 

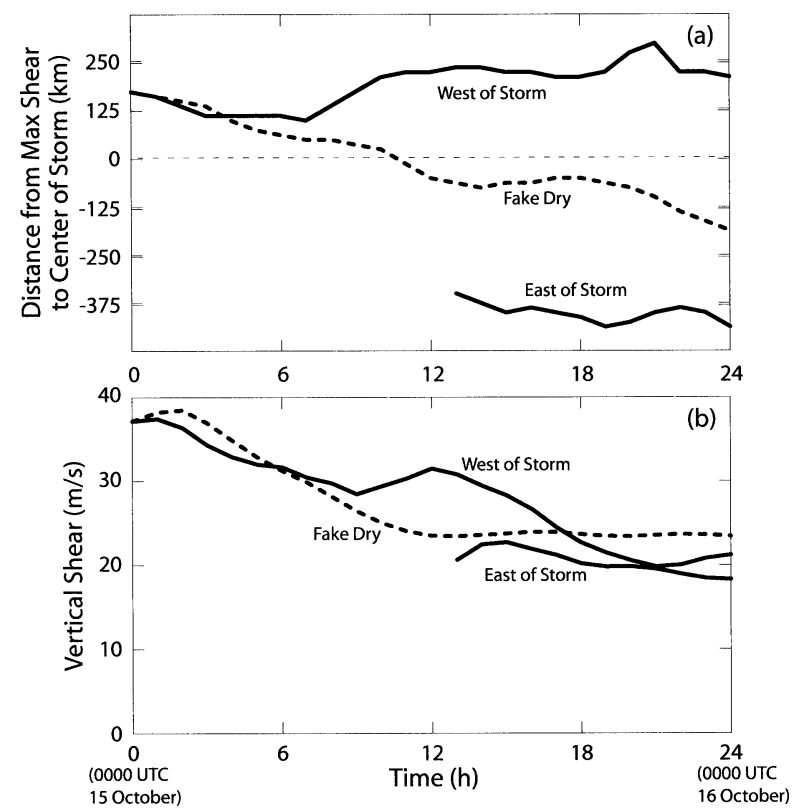

FIG. 15. (a) Zonal distance between surface storm center and location of maximum vertical shear (900-200-hPa layer); (b) magnitude of maximum vertical shear corresponding to (a).

As noted, the transition to a warm-core structure occurred after the vertical shear over the mesoscale center decreased to below about $10 \mathrm{~m} \mathrm{~s}^{-1}$. As seen in Fig. 11c, the decrease in vertical shear occurred rapidly at first between 6 and $12 \mathrm{~h}$ (0600-1200 UTC 15 October), then more gradually to its minimum value around $25 \mathrm{~h}(0100$ UTC 26 October). The initial decrease occurred on the timescale of the development of the convective band, suggesting a prominence of diabatic effects.

The change in the shear over the storm center may be decomposed into dynamical (adiabatic and diabatic) and translational effects, the latter being the movement of the storm center relative to a nearly steady pattern of deep-layer shear. To help understand the relative importance of these effects in reducing the shear, we considered a sensitivity simulation with diabatic heating due to phase changes of water suppressed. The vertical shear over the center from the "fake-dry" simulation decreased to about $23 \mathrm{~m} \mathrm{~s}^{-1}$ (recall Fig. 11c) after $24 \mathrm{~h}$ (0000 UTC 16 October).

By computing a time series of zonal distance from the storm center to the location of the maximum shear at the same latitude (Fig. 15a) for both the control and fake-dry simulations, it is apparent that storm in the fake-dry simulation began slightly toward the east (warm) side of the maximum shear and drifts to the west (cool) side with time. In the control simulation, the storm never moved beneath the maximum shear. Instead, the pattern of vertical shear was dramatically rearranged. The initial maximum shear to the west of the surface cyclone was displaced farther west relative to the center and a new shear maximum of comparable

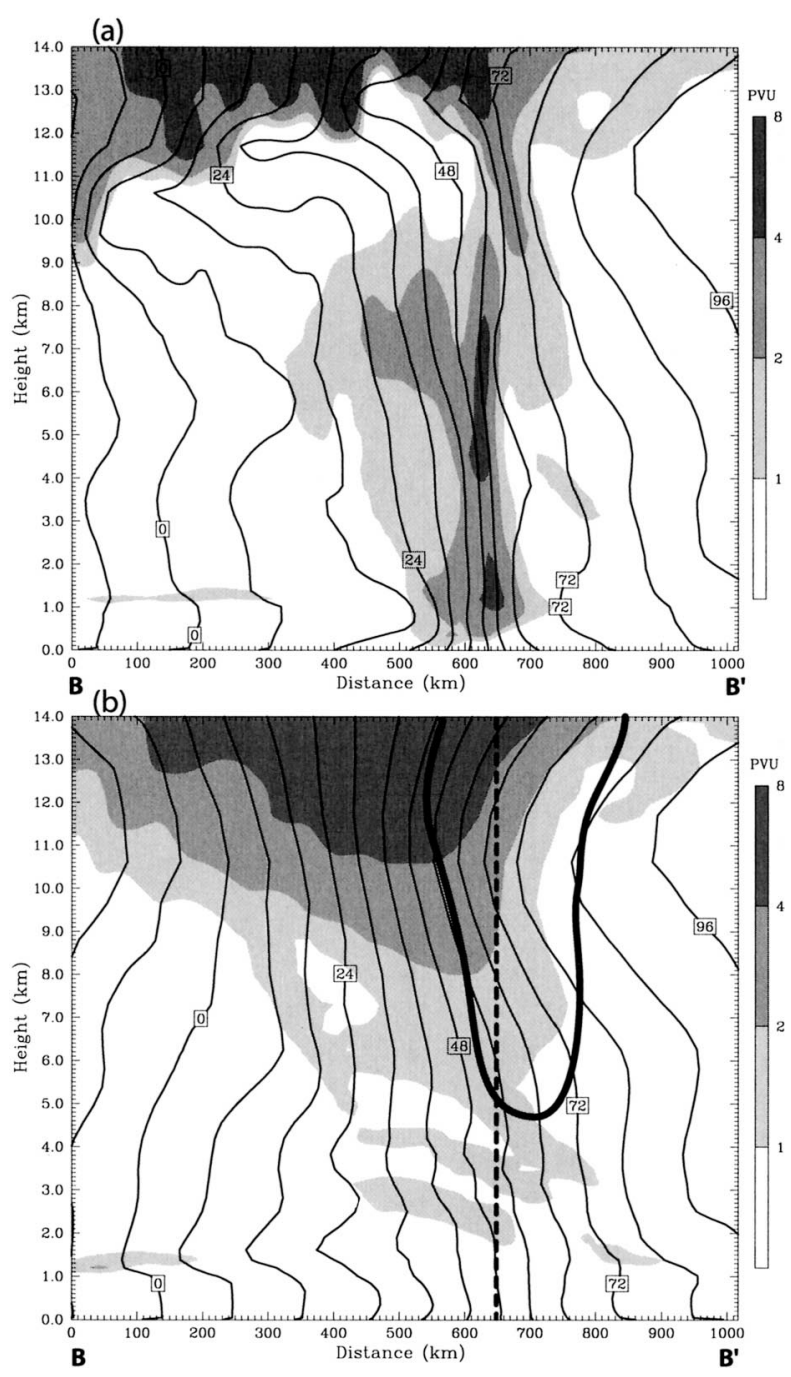

FIG. 16. Cross sections (see Fig. 10) PV and absolute momentum (see text) valid 1200 UTC 15 Oct from (a) the control simulation and (b) the fake-dry simulation. Heavy, dashed line in (b) is a reference vertical line at the $x$ coordinate of the storm center. The heavy solid line in (b) bounds approximately the region with a positive zonal PV gradient.

strength appeared to the east of the center by $13 \mathrm{~h}$ (1300 UTC 15 October). Note that the vertical shear to the west and east of the center in the control simulation retained a similar magnitude to the shear in the fakedry simulation (Fig. 15b). Thus, the key to reducing the shear over the pre-Michael disturbance was the spatial displacement of vertical shear from the storm center rather than a global reduction in shear magnitude. This displacement depended fundamentally on diabatic processes. Furthermore, the rate of displacement was much larger than the relative movement of the surface cyclone, implying that translational effects were a secondary aspect of shear reduction over the storm center.

The cross sections in Fig. 16 show that the deep, cyclonic PV anomaly located slightly to the west of the 
surface cyclone in the fake-dry simulation (Fig. 16b) was redistributed in the control simulation (Fig. 16a). Because surfaces of absolute momentum- $-M=v+f x$, where $v$ is the velocity normal to the cross section and $x$ the direction toward the right-are parallel to the absolute vorticity vector, the redistribution of PV takes place along $M$ surfaces. On the $48 \mathrm{~m} \mathrm{~s}^{-1} M$-line in Fig. $16 \mathrm{a}$, we see clearly the deficit of PV in the upper troposphere and a large increase in the lower troposphere in the control simulation relative to the fake-dry simulation, consistent with the expected effect of latent heating in vertical shear (Raymond 1992).

To the extent that an invertibility relationship exists$q=\mathcal{L}(\Psi)$, where $q$ is the $\mathrm{PV}, \Psi$ the streamfunction, and $\mathcal{L}$ an elliptic operator-one can equally use the relationship $q_{x}=\mathcal{L}^{\prime}(v)$ to relate the meridional wind to the zonal gradient of PV. Here, the subscript $x$ denotes differentiation, and $\mathcal{L}^{\prime}$ is simply the derivative of $\mathcal{L}$ with respect to $x$. By virtue of the general properties of elliptic equations, we expect a local minimum (maximum) in $q_{x}$ will be roughly collocated with a maximum (minimum) in $v$. The maximum negative gradient in PV above the storm center in the fake-dry simulation is therefore collocated with the meridional jet, beneath which there is strong meridional wind shear. By redistributing the PV through diabatic heating, the PV gradient above the cyclone is reduced and therefore so is the meridional jet and tropospheric meridional shear. Furthermore, the outflow below the tropopause tends to displace the PV gradient laterally, also contributing to the reduction of shear over the storm center in the middle and upper troposphere.

One may also note that, to the extent that the flow is quasi-two-dimensional, $M$ is approximately conserved and therefore becomes well mixed where convection occurs. Because the vertical shear is equivalent to $M_{z}$, mixing of $M$ removes the shear. The PV and $M$-surface perspectives produce the equivalent result, and from either it is clear that vigorous latent heating, organized on the mesoscale, is central to the removal of vertical shear. We conclude that the reduction of vertical shear over the center of the pre-Michael disturbance to a value below the empirical threshold for tropical cyclone intensification is crucially dependent on the diabatic rearrangement of PV within the storm itself.

\section{Synthesis}

We found significant baroclinic precursors to all Atlantic tropical cyclones developing poleward of $20^{\circ} \mathrm{N}$ during the latter half of the hurricane seasons 2000 and 2001. We hypothesize that the evolution of maritime, baroclinic cyclones tends to produce environments conducive to tropical cyclogenesis. In other words, the initially strongly sheared environment, hostile to tropical cyclone formation, is drastically modified as the incipient cyclone evolves such that, after a period of roughly one day, the vertical shear is eroded and a robust, finite amplitude vortex is present in the lower troposphere, free to organize fluxes of moist entropy from the ocean surface. It appears that the initial cyclogenesis must equilibrate and this is expedited by diabatic effects, which transform the initial upper-tropospheric troughridge couplet into a structure with little shear above the storm center.

It appears inaccurate to think of the baroclinic conversions of energy within the initial cyclogenesis as the most important aspect of the baroclinic precursor. Rather, it appears that the baroclinic system is the conduit for organized convection and its associated heating to emerge. Diana in 1984 provided an excellent example in which the baroclinic cyclogenesis was modest yet facilitated organized convection that led to coherent vortices in the lower troposphere. These, in turn, formed the seed for the tropical cyclone (e.g., Davis and Bosart 2001).

Even in the cases featuring the strongest baroclinic precursors, such as Michael in 2000 and Karen in 2001, the baroclinic conversions of energy are still minor compared to the diabatic effects (note that the disturbance in the fake-dry simulation of the pre-Michael disturbance weakened monotonically from the beginning). The key is the focusing of latent heat release. In Michael, this was attributable to moistening and thermodynamic destabilization forced by mesoscale ascent within the frontal cyclone. A qualitatively similar, though weaker, signal could be inferred from the 24case composite of northern Caribbean developing tropical depressions described in Bracken and Bosart (2000).

There appears an additional set of cases in which baroclinic effects may be important, though the overall structure is not readily identified with the composite structure presented by Bracken and Bosart (2000) that features a baroclinic wave. Danny in 1997 (Molinari et al. 2002) and Gabrielle in 2001 featured midtropospheric vortices prior to tropical cyclogenesis. Deep convection organized on the downshear side of these vortices in accord with theory (Raymond 1992) and subsequently led to surface development. While the dynamics responsible for the development of a surface circulation in these cases and others like them is a matter of continuing research, without shear, it is likely that convection would not have been as organized as was observed and therefore the path to surface cyclogenesis might have required more time or not occurred at all.

\section{Conclusions}

The authors have examined numerous subtropical and extratropical cyclones during the latter half of the hurricane seasons of 2000 and 2001 in order to better understand how tropical cyclogenesis can take place in environments that initially maintain a vertical wind shear as large as $30 \mathrm{~m} \mathrm{~s}^{-1}$ averaged through the troposphere. In all cases that transition to tropical cyclones, 
the vertical wind shear over the incipient storm center decreased dramatically during the baroclinic development that preceded tropical cyclogenesis. The range of deep-tropospheric vertical shear $(900-200 \mathrm{hPa})$ attained prior to tropical transformation is typically from nearly zero up to about $10 \mathrm{~m} \mathrm{~s}^{-1}$, roughly consistent with general results on the maximum shear that can allow tropical cyclogenesis (e.g., Gallina and Velden 2002).

In the cases that do not transition to a warm-core structure (essentially the defining element of tropical cyclogenesis), either the large vertical shear over the center is maintained or the subtropical cyclone drifts over cool water before the shear decreases. In the cases where shear is maintained, it appears that multiple shortwave troughs are involved, spaced too closely to allow equilibration (occlusion) of the subtropical cyclone.

We examined the formation of Hurricane Michael in 2000 in detail. We presented evidence that Michael transitioned to a tropical storm several hours prior to its official tropical designation by the TPC. The pre-Michael disturbance was a frontal wave that amplified and occluded, resembling strongly the secondary frontal cyclogenesis discussed by Thorncroft and Hoskins (1990). Simulations with the MM5 model reproduced the transition of Michael to a warm-core disturbance. This transformation occurred after the vertical shear over the surface circulation center decreased from 30 to $8-10 \mathrm{~m} \mathrm{~s}^{-1}$ within $24 \mathrm{~h}$. We diagnosed the decrease in shear in terms of potential vorticity redistribution from diabatic heating effects. Outflow at the tropopause laterally displaced the gradients of PV away from the surface circulation. Nonconservation of PV effectively transferred middle-upper-tropospheric anomalous PV, displaced slightly west of the storm center, to low levels in phase with the storm center. Because gradients of PV are related to velocity by an elliptic operator, removal of a PV gradient in the middle and upper troposphere is synonymous with reducing the tropospheric vertical wind shear. To the extent that the ambient flow is relatively two-dimensional, the removal of vertical shear can be viewed in terms of mixing quasi-conserved absolute momentum in the vertical through organized, deep convection. The strong outflow at the tropopause is directed down the gradient of ambient absolute momentum, generally toward higher PV, and hence displaces the PV gradient laterally away from the updraft. Although these processes were examined for a single case, it is probable that a similar dynamical chain of events occurs in other transitioning or even more mature tropical cyclones, such that the ability of a given storm to modify its own environment should be considered a critical element affecting its subsequent development.

Because the pre-Michael cyclone was a robust baroclinic cyclogenesis, it was able to produce a finiteamplitude mesoscale surface cyclone such that the transition to a warm-core structure could begin almost as soon as the shear weakened. For cases beginning with weaker extratropical disturbances, such as Humberto in
(2001) and Diana in 1984, the transformation to a tropical cyclone involved an intermediate step of organizing convection which, in turn, produced a coherent mesoscale vortex capable of growth through air-sea interaction. The distinction may be the degree to which the character of organized convection is imposed by frontal circulations in strongly baroclinic cases, versus internally generated in weakly "forced" cases. Therefore, in the cases with weak precursor disturbances, the fundamental issue in need of further investigation is how convection produces the necessary mesoscale vortices to achieve a self-amplifying disturbance.

Acknowledgments. The authors would like to thank Dr. Stanley Trier of NCAR and Dr. Michael Dickinson of the University at Albany SUNY for their helpful reviews of earlier versions of this manuscript. Lance $\mathrm{F}$. Bosart was supported by Grant NSF ATM-9612485.

\section{REFERENCES}

Bosart, L. F., and J. Bartlo, 1991: Tropical cyclone formation in a baroclinic environment. Mon. Wea. Rev., 119, 1979-2013.

Bracken, E., and L. F. Bosart, 2000: The role of synoptic-scale flow during tropical cyclogenesis over the North Atlantic Ocean. Mon. Wea. Rev., 128, 353-376.

Braun, S. A., and W.-K. Tao, 2000: Sensitivity of high-resolution simulations of Hurricane Bob (1991) to planetary boundary layer parameterizations. Mon. Wea. Rev., 128, 3941-3961.

Davis, C. A., and K. A. Emanuel, 1991: Potential vorticity diagnostics of cyclogenesis. Mon. Wea. Rev., 119, 1929-1953.

__ , and L. F. Bosart, 2001: Numerical simulations of the genesis of Hurricane Diana. Part I: Control simulation. Mon. Wea. Rev., 129, 1859-1881.

- , and -2002 : Numerical simulations of the genesis of Hurricane Diana. Part II: Sensitivity of track and intensity prediction. Mon. Wea. Rev., 130, 1100-1124.

DeMaria, M., J. A. Knaff, and B. H. Conell, 2001: A tropical cyclone genesis parameter for the tropical Atlantic. Wea. Forecasting, 16, 219-233.

Donnelly, W. J., J. R. Carswell, R. E. McIntosh, P. S. Chang, J. Wilkerson, F. Marks, and P. G. Black, 1999: Revised ocean backscatter models at $\mathrm{C}$ and $\mathrm{Ku}$ band under high-wind conditions. J. Geophys. Res., 104 (C5), 11 485-11 497.

Dudhia, J., 1989: Numerical study of convection observed during the winter monsoon experiment using a mesoscale two-dimensional model. J. Atmos. Sci., 46, 3077-3107.

Emanuel, K. A., 1986: Air-sea interaction theory for tropical cyclones. Part I: Steady-state maintenance. J. Atmos. Sci., 43, 585604.

_ 1995 : Sensitivity of tropical cyclones to surface exchange coefficients and a revised steady-state model incorporating eye dynamics. J. Atmos. Sci., 52, 3969-3976.

Gallina, G. M., and C. S. Velden, 2002: Environmental vertical wind shear and tropical cyclone intensity change utilizing enhanced satellite derived wind information. Preprints, 25th Conf. on Hurricanes and Tropical Meteorology, San Diego, CA, Amer. Meteor. Soc., 172-173.

Gray, W. M., 1968: Global view of the origin of tropical disturbances and storms. Mon. Wea. Rev., 96, 669-700.

Grell, G. A., J. Dudhia, and D. R. Stauffer, 1994: A description of the Fifth-Generation Penn State/NCAR Mesoscale Model (MM5). NCAR Tech. Note TN-398+STR, 122 pp. [Available 
from UCAR Communications, P.O. Box 3000, Boulder, CO 80307.]

Kain, J. S., and J. M. Fritsch, 1993: Convective parameterization for mesoscale models: The Kain-Fritsch scheme. The Representation of Cumulus Convection in Numerical Models, Meteor. Monogr., No. 46, Amer. Meteor. Soc., 165-170.

Molinari, J., D. Vollaro, and K. Corbosiero, 2002: Genesis of a hurricane in a sheared environment. Preprints, 25th Conf. on Hurricanes and Tropical Meteorology, San Diego, CA, Amer. Meteor. Soc., 393-394.

Montgomery, M. T., and B. F. Farrell, 1993: Tropical cyclone formation. J. Atmos. Sci., 50, 285-310.

Palmén, E., and C. W. Newton, 1969: Atmospheric Circulation Systems. Academic Press, 603 pp.

Powers, J. G., and C. A. Davis, 2002: A cloud-resolving, regional simulation of tropical cyclone formation. Atmos. Sci. Lett., 3, doi:10.1006/asle.2002.0054
Raymond, D. J., 1992: Nonlinear balance and potential vorticity thinking at large Rossby number. Quart. J. Roy. Meteor. Soc., 118, 987-1015.

Schade, L. R., 2000: Tropical cyclone intensity and sea surface temperature. J. Atmos. Sci., 57, 3122-3130.

Schultz, P., 1995: An explicit cloud physics parameterization for operational numerical weather prediction. Mon. Wea. Rev., 123, 3331-3343.

Thorncroft, C. D., and B. J. Hoskins, 1990: Frontal cyclogenesis. J. Atmos. Sci., 47, 2317-2336.

,-- , and M. E. McIntyre, 1993: Two paradigms of baroclinicwave life-cycle behaviour. Quart. J. Roy. Meteor. Soc., 119, 1756

Vega, A. J., and M. S. Binkley, 1994: Tropical cyclone landfall in the United States 1960-1989. Natl. Wea. Dig., 19, 14-26.

Zhang, D.-L., and R. A. Anthes, 1982: A high-resolution model of the planetary boundary layer-Sensitivity tests and comparisons with SESAME-79 data. J. Appl. Meteor., 21, 1594-1609. 